\title{
The Activity of Primary Motor Cortex Corticospinal Neurons during Tool Use by Macaque Monkeys
}

\author{
Marsha M. Quallo, ${ }^{\star}$ Alexander Kraskov, ${ }^{\star}$ and Roger N. Lemon \\ Sobell Department of Motor Neuroscience and Movement Disorders, University College London Institute of Neurology, London WC1N 3BG, United \\ Kingdom
}

It has been suggested that the distinctive capacity of some nonhuman primates to use tools may reflect a well-developed corticospinal system and, in particular, direct cortico-motoneuronal (CM) connections to hand muscles. We investigated the activity of corticospinal neurons in the primary motor cortex hand area during the use of a tool by two adult macaque monkeys. They used a light rake to retrieve food rewards placed in their extrapersonal space. An analysis of EMG activity showed that the rake task involved a complex interaction of muscles acting on the digits, hand, and arm. Sixty-nine corticospinal neurons were identified antidromically as pyramidal tract neurons (PTNs). When tested on the rake task, most $(64$ of $69 ; 93 \%)$ showed a significant modulation of their discharge during at least one of three task periods: grasping the rake, projecting it beyond the food reward, and then pulling it back to retrieve the reward. Discharge patterns were heterogeneous, and many PTNs showed significant suppression of discharge during raking. Seventeen of the 69 PTNs recorded during the rake task were further identified as CM cells, exerting clear postspike facilitation on digit muscles, demonstrating that the $\mathrm{CM}$ system contributes to the skilled use of tools. We compared the activity of each PTN on the rake task with that during precision grip. Most PTNs (90\%) modulated their activity significantly for both tasks, demonstrating that PTNs activated by a task involving fractionated movements of the digits are also recruited during rake use, although there were often contrasting patterns of PTN recruitment and muscle activity for the two tasks.

\section{Introduction}

In primates, the primary motor cortex (M1) (Brodmann area 4) is the major contributor to the corticospinal tract, the major descending pathway influencing skilled hand movements, and damage to these structures by stroke or spinal injury has devastating consequences for all those functions that depend on control of the hand (Lawrence and Kuypers, 1968; Dum and Strick, 1991; Porter and Lemon, 1993). A subset of corticospinal projections make direct, cortico-motoneuronal (CM) connections with spinal motoneurons (Porter and Lemon, 1993; Lemon, 2008), and these connections, which are unique to primates (Lemon and Griffiths, 2005), are chiefly derived from M1 (Rathelot and Strick, 2006, 2009).

There is considerable evidence that those primate species with a well-developed corticospinal system, including CM projec-

\footnotetext{
Received March 1, 2012; revised Sept. 11, 2012; accepted Sept. 13, 2012

Author contributions: R.N.L. designed research; M.M.Q., A.K., and R.N.L. performed research; M.M.Q., A.K., and R.N.L. analyzed data; M.M.Q., A.K., and R.N.L. wrote the paper.

This study was supported by The Wellcome Trust. We also acknowledge grant support from the National Centre for the 3Rs for development of the implanted headpiece used in this study and to the Medical Research Council for supporting a studentship (M.M.Q.). We particularly thank Prof. Atsushi Iriki for his collaboration and advice throughout this study, which was supported by an Institute of Physical and Chemical Research collaborative grant. Ed Bye, Victor Baller, Spencer Neal, Chris Seers, Robin Richards, and Sam Shepherd are thanked for expert technical assistance and Dr. Numa Dancause, Robin Brown, and Nitin Sahi for their assistance with some of the recordings and data analysis.

${ }^{*}$ M.M.Q. and A.K. contributed equally to this work.

Correspondence should be addressed to Dr. Roger N. Lemon, Sobell Department of Motor Neuroscience and Movement Disorders, University College London Institute of Neurology, Queen Square, London WC1N 3BG, UK. E-mail:r.lemon@ucl.ac.uk.

DOI:10.1523/JNEUROSCI.1009-12.2012

Copyright $\odot 2012$ the authors $\quad 0270-6474 / 12 / 3217351-14 \$ 15.00 / 0$
}

tions, are characterized by the ability to perform fine motor skills using independent finger movements (Heffner and Masterton, 1975; Lemon and Griffiths, 2005). Some of the more dexterous primates use tools (Chiang, 1967; Visalberghi et al., 1995; van Schaik et al., 1999; Gumert et al., 2009) defined as the manipulation of an object to change the position or form of another object (Beck, 1980). It has been speculated that the development of the CM system was part of the evolutionary change that led to improved dexterity (Phillips, 1971; Maier et al., 2005), providing one important capacity that contributed to tool use and manufacture in primates (van Schaik et al., 1999). It is now well established that captive macaque monkeys can learn to use a rake as a tool, using it to retrieve food rewards placed just beyond their reach (Warden et al., 1940; Shurcliff et al., 1971; Iriki et al., 1996). The task developed by Iriki and colleagues has allowed a number of the sensorimotor mechanisms involved in tool use to be explored for the first time (Obayashi et al., 2002; Hihara et al., 2006; Quallo et al., 2009).

It is known that corticospinal neurons, including those with CM connections, are recruited during relatively independent finger movements, such as the precision grip (Muir and Lemon, 1983; Maier et al., 1993; Bennett and Lemon, 1996; Schieber and Rivlis, 2005). However, evidence of corticospinal involvement in tool use is so far lacking. A specific objective of this study was to investigate whether identified corticospinal neurons recorded in macaque M1 hand area showed a comparable level of activity during the rake task as during precision grip. We initially identified corticospinal neurons as pyramidal tract neurons (PTNs) by their antidromic response to stimulation of the medullary pyra- 
A
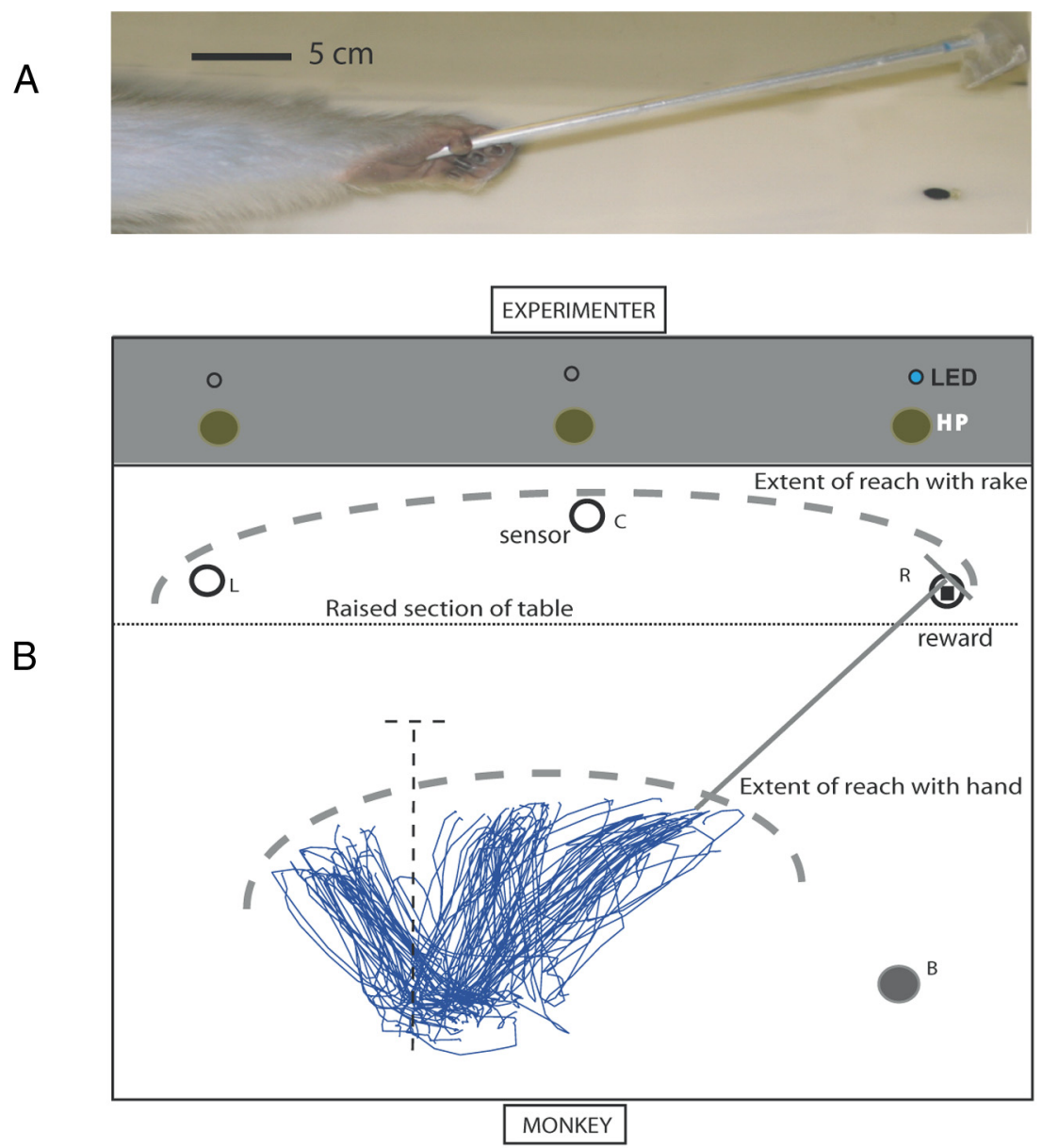

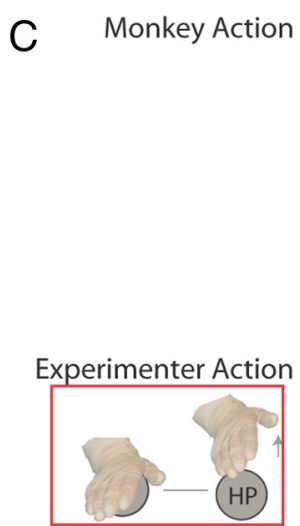

PERIODS 1 Baseline

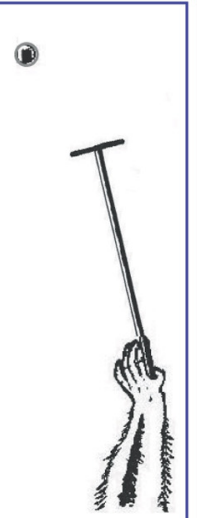

2

Rake pick-up

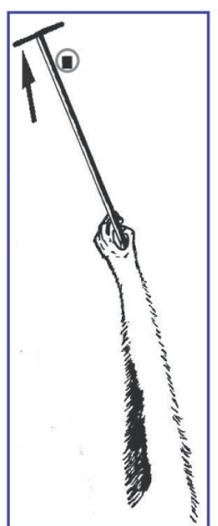

3

Reach \& swing

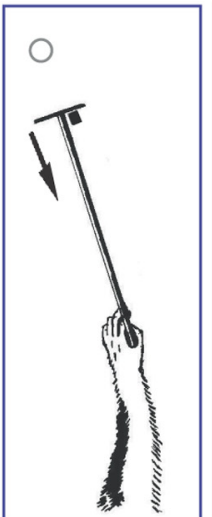

4

Return, rake crosses sensor

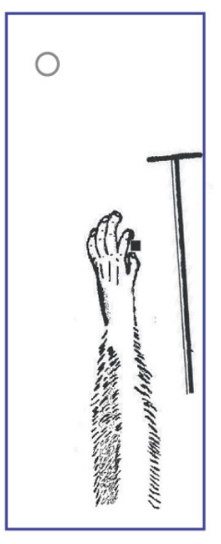

Food pick-up
TIME

Figure 1. Rake task. $A$, Photograph of M43 holding the rake. Note the grasp used, with the shaft of the rake held between the flexed thumb and the other digits. A food reward was placed at a target position on the table (black circle at bottom right), and a sensor device was embedded in the table below the target. $\boldsymbol{B}$, Table used for the rake task. The experimenter sat on the far side of the table $(62 \times 68 \mathrm{~cm})$ facing the monkey. The monkey raked with its left hand and rested its right hand on block B. On the experimenter's side of the table (gray zone) were three home-pad (HP) pressure sensors. At the beginning of each trial, the experimenter positioned the rake (dashed outline) close to the monkey's left hand. An LED above one of the home pads indicated which target should be baited for the next trial: left $(L)$, right $(R)$, and central $(C)$ to the monkey. Targets were selected in a randomized sequence. The experimenter, holding the food reward for that trial, rested her hand on the appropriate home pad. A tone sound cued the experimenter to place the food at the instructed target. Targets were positioned in an arc (gray dashed line) $\sim 42 \mathrm{~cm}$ from the monkey on a section of the table that was slightly raised by $2.2 \mathrm{~mm}$. Once the food reward was placed at a target, the monkey picked up the rake and used it to retrieve the reward. Passage of the rake head over the target was detected by magnetic sensors underneath each target. The traces superimposed over the table surface show the trajectory of the monkey's hand from the start of the trial to the maximum reach position in a single recording session (monkey M43); these traces were midal tract and then recorded their activity while macaques used a light rake to retrieve food rewards. We compared the discharge of each PTN on the rake task with that recorded while monkeys performed a precision grip between index finger and thumb. M1 PTNs that are recruited during the latter are presumably concerned with movements of the most distal parts of the limb and include CM cells projecting directly to motoneurons innervating digit muscles (Lemon, 2008). It was of interest to discover whether these PTNs were also activated during the rake task, which involves movement of both the proximal (shoulder and elbow) and distal (hand and digits) limb. We found that almost all PTNs, including 17 that were confirmed to be CM cells, were as strongly recruited on the precision grip task as on the rake task, confirming the involvement of the primate $\mathrm{CM}$ system in the use of a tool.

\section{Materials and Methods \\ Monkeys}

Two adult purpose-bred Rhesus (Macaca mulatta) monkeys [M41 (monkey R), male, 5 years old, $7.8 \mathrm{~kg}$; and M43 (monkey E), female, 6 years old, $5.1 \mathrm{~kg}$ ] were used. All experimental procedures were approved by the Local Ethical Procedures committee and performed in accordance with the United Kingdom Animals (Scientific Procedures) Act. Monkeys were trained to perform both the rake and the precision grip tasks with the left hand. Monkeys were trained for several months (in M41, 7 months; M43, 9 months) before recordings began.

$\leftarrow$

derived from markers on the back of the monkey's hand that were captured with a digital video camera mounted above the raking table. C, Different periods of the rake task. Period 1 (Baseline) began after the experimenter had placed a reward at one of the targets and depressed the home pad. This period started $750 \mathrm{~ms}$ before the experimenter released her hand from the home pad; during this baseline period, the monkey was required not to move. Period 2 (Rake pick-up) began when the experimenter released the home pad and uncovered the reward, which cued the monkey to pick up the rake from its start location (approximate position indicated by dashed line). This period was defined as occupying the first half of the interval between HPR and the sensor signal and lasted $\sim 350-500$ ms. Period 3 (Reach \& swing) was defined as taking up the second half of this interval. During this period, the monkey extended the rake, lifted it over the raised section, and swung the head of the rake behind the reward. The food reward is shown as a black square over the target (black circle). Period 4 (Return, rake crosses sensor) was defined as lasting from the time the rake head crossed the sensor to $250 \mathrm{~ms}$ later. Period 5 (Food pick-up) was defined as lasting for the period 250 to $1000 \mathrm{~ms}$ after the rake crossed the sensor; the monkey released the rake and collected the reward with the same (left) hand. Drawings based on still shots from the video camera. 


\section{Rake task}

A white worktable, $62 \times 68 \mathrm{~cm}$, placed in front of the monkey at waist height, was used (Fig. 1B). The monkey was trained to use its left hand to pick up a light rake and use it to retrieve food rewards placed just beyond its peripersonal space. The rake (Fig. $1 \mathrm{~A}$ ) had a $30 \mathrm{~cm}$ shaft and a $10 \times 6$ $\mathrm{cm}$ rectangular head, and it weighed $38 \mathrm{~g}$. A small food reward could be placed over one of three targets on a slightly raised section $(2.2 \mathrm{~mm}$ height) of the table, $42 \mathrm{~cm}$ from the monkey's side of the table. The targets lay to the right (Fig. $1 B, \mathrm{R})$, left $(\mathrm{L})$, and directly ahead of the monkey (center, C). The left and right targets subtended an angle of $\sim 26^{\circ}$ to the monkey. Under each target lay a magnetic sensor. When the rake head, which carried a number of small magnets, passed over one of these sensors, a pulse was generated. The experimenter's section of the table (Fig. $1 B$, shaded area at top) carried three home-pad pressure sensors that were located just beyond the three targets and were operated by the experimenter. Next to each pressure sensor was an LED, not visible to the monkey, which was used to indicate the pseudorandom order in which the targets were baited for each trial. A small round block (Fig. 1B, B) was provided on the right side of the worktable for the monkey to rest its non-raking hand.

At the beginning of each trial, the experimenter positioned the rake close to the monkey's left hand (approximate position indicated by dashed outline in Fig. $1 B$ ) and then placed a small food reward on the target indicated by the LED; the experimenter depressed the home pad, keeping the food covered with her fingers. After a $1 \mathrm{~s}$ delay (mean over sessions, $1.09 \mathrm{~s}$ ), a tone cued the experimenter to simultaneously release her hand from the home pad and remove her hand from the food (Fig. $1 C$, period 1). This was in turn the cue for the monkey to pick up the rake, lift the head of the rake over the raised section of the table, swing it just beyond the reward, and then pull the rake to retrieve the reward (Fig. $1 C$, Monkey action, periods 2-4). An event pulse was generated as the rake head was pulled over the sensor. The monkey then released the rake, picked up the food reward with its left hand (Fig. $1 C$, period 5), and transferred it to its mouth. The experimenter then replaced the rake in its start position. The next trial began after the monkey had eaten the reward and returned its hand to the worktable, resting it close to the rake and awaiting the experimenter's cue for the trial to start. A digital video camera mounted above the table was used to monitor the monkey's performance on the task.

\section{Precision grip task}

Both monkeys were also trained to use a precision grip manipulandum, using the index finger and thumb to squeeze two spring-loaded levers (Baker et al., 2001). The levers were mounted in a manipulandum positioned just in front of the monkey. Monkeys were trained to move each lever independently into a target zone (defined electronically) and hold it there for 1s. Target positions were $\sim 6-9 \mathrm{~mm}$ from the start position, and the force needed to hold them in this position was $\sim 0.3 \mathrm{~N}$. This hold period generated an "end-hold" pulse and cued the monkey to release the levers. On completion of a successful trial, the monkey was rewarded by the experimenter with a piece of food. Monkeys were not rewarded on every trial for this task and would perform two or three trials before receiving a reward.

\section{Structural MRI}

A structural MRI scan of each monkey was obtained in the early stages of training. Monkeys were scanned under deep ketamine/domitor anesthesia. Monkeys were placed in a plastic stereotaxic head holder. The scans were performed on a GE Signa $1.5 \mathrm{~T}$ scanner with circular receiving surface head coils and using spin echo (2D) and gradient echo (3D volume) during data acquisition. Voxel dimensions were $0.7 \times 0.7 \times 0.7$ $\mathrm{mm}$. During scanning, heart and respiration rates and end-tidal $\mathrm{pCO}_{2}$ were monitored continuously. Using custom-made software (3D Workstation, Medical Graphics, University College London), a 3D rendering of the calvarium surface was created. In addition, a 3D rendering of the cortical surface was created that was used to guide the placement of recording chambers and aided the planning of electrode penetrations.

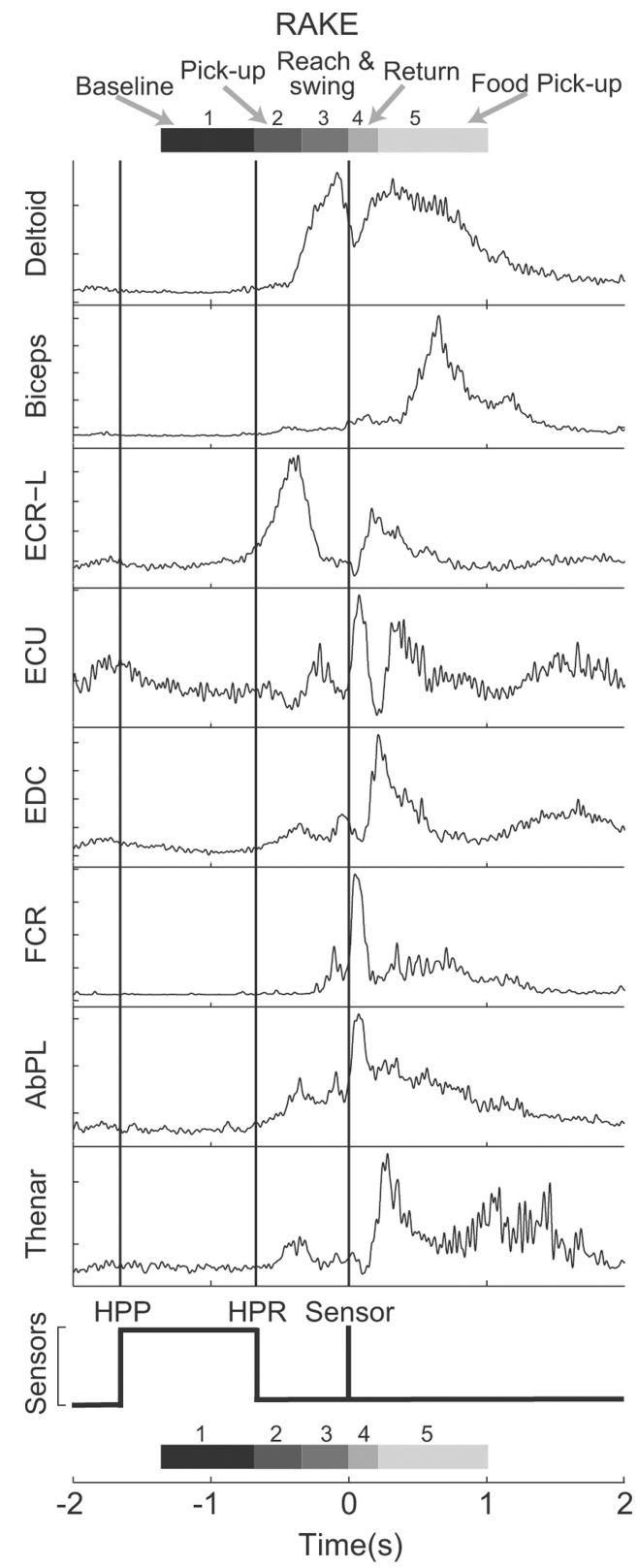

Figure 2. EMG activity during task. Rectified, smoothed (low-pass filter, $30 \mathrm{~Hz}$ ) and averaged EMG from eight muscles referenced to the moment the rake crossed the right sensor (time 0 ) are shown ( $n=30$ trials); EMG amplitude has been normalized to the maximum EMG for each muscle. In the bottom trace are signals indicating diagrammatically when the experimenter's home pad was pressed (HPP) and then released (HPR) and when the rake head passed over the sensor. Because of trial-by-trial variation in the timing of these events, the events shown here and the gray scale bar (at top and bottom) indicating the task periods $1-5$ (see Fig. 1C) are an idealized representation.

\section{Surgical implantation}

Monkeys underwent three main surgical procedures, all performed in aseptic conditions under deep anesthesia induced with ketamine/domitor (intramuscularly) and maintained with $2-2.5 \%$ isoflurane in 50:50 $\mathrm{O}_{2} / \mathrm{N}_{2} \mathrm{O}$. The first surgery was the implantation of a headpiece: in M41 this was made of stainless steel and in M43 from Tecapeek. Tecapeek is a high-strength biocompatible and MR-compatible thermoplastic, and this headpiece was custom fitted to the skull surface using the MRI-based model.

The second surgery was the implantation of 12 chronic EMG patch electrodes sutured over hand, arm, and digit muscles on the left side: first dorsal interosseous (1DI), thenar, abductor digiti minimi, flexor digitorum profundus (FDP), flexor carpi ulnaris, flexor carpi radialis (FCR), 
abductor pollicis longus (AbPL), extensor digitorum communis (EDC), extensor carpi ulnaris (ECU), extensor carpi radialis longus (ECR-L), biceps, and anterior deltoid, using the method described by Brochier et al. (2004). The third surgery involved the mounting of a recording chamber $(20 \times 10 \mathrm{~mm})$ positioned to give access to both the $\mathrm{F} 5$ hand area (inferior limb of arcuate sulcus) and the M1 hand area (middle third of the central sulcus) in the right hemisphere. The top of the chamber was $\sim 5-7$ $\mathrm{mm}$ above the exposed dura. The right medullary pyramid was chronically implanted with a pair of fine tungsten stimulating electrodes, for subsequent antidromic identification of PTNs during recording sessions (Kraskov et al., 2009). The final position of the electrodes was adjusted for the lowest threshold antidromic volley recorded from the ipsilateral M1 (M41, 20 and $20 \mu \mathrm{A}$ and M43, 22 and $45 \mu \mathrm{A}$ for posterior and anterior electrodes, respectively).

\section{Recording}

A 16-channel Thomas Recording drive was used. Three to five glass-insulated platinum electrodes (shank diameter, $80 \mu \mathrm{m}$ ) were loaded into the drive; the inter-electrode spacing was $300 \mu \mathrm{m}$. The drive was securely fixed to the metal rig in which the monkey sat. At the beginning of each recording session, the stereotaxic position of the drive was calculated using up to five fiducial markers on the chamber lid. The surface location of the penetration was calculated and marked on a computergenerated chamber map, which was based on measurements made at surgery of the stereotaxic coordinates of the fiducial markers. Stereotaxic measurements of central and arcuate sulci determined from MRI and at surgery were superimposed on the same chamber map. After preamplification $(20 \times$; Thomas Recording drive), the signals from each electrode were further amplified (typically $500 \times$ or $1000 \times$ ) and bandpass filtered $(0.3-6 \mathrm{kHz})$. Data were acquired using an analog-to-digital card (PCI6071E; National Instruments) at $25 \mathrm{kHz}$ sampling rate and were recorded together with EMG activity sampled at $5 \mathrm{kHz}$ and experimental events, including home pad, sensor signals, and digit position sampled at $1 \mathrm{kHz}$. After recording a full set of data, intracortical microstimulation (ICMS) was delivered to the electrode at the same depth at which recordings were made. An isolated stimulator (Neurolog NL800 stimulus isolator; Digitimer) delivered trains of repetitive ICMS through each recording electrode ( 13 pulses at $333 \mathrm{~Hz}$, intensity typically up to $40 \mu \mathrm{A}$, duty cycle of $0.5 \mathrm{~Hz}$ ). After each recording session, the exposed dura was briefly ( $5 \mathrm{~min}$ ) covered with a solution of 5-fluorouracil (Faulding Pharmaceuticals) to reduce growth of fibroblasts and the resulting accumulation of tough connective tissue on the dura (Spinks et al., 2003).

Selection of neurons and identification of PTNs

The selection of neurons for recording was based entirely on their antidromic identification as PTNs and not on their activity during the trained tasks. At the beginning of each session, a 250-300 $\mu \mathrm{A}$ search each muscle.
A
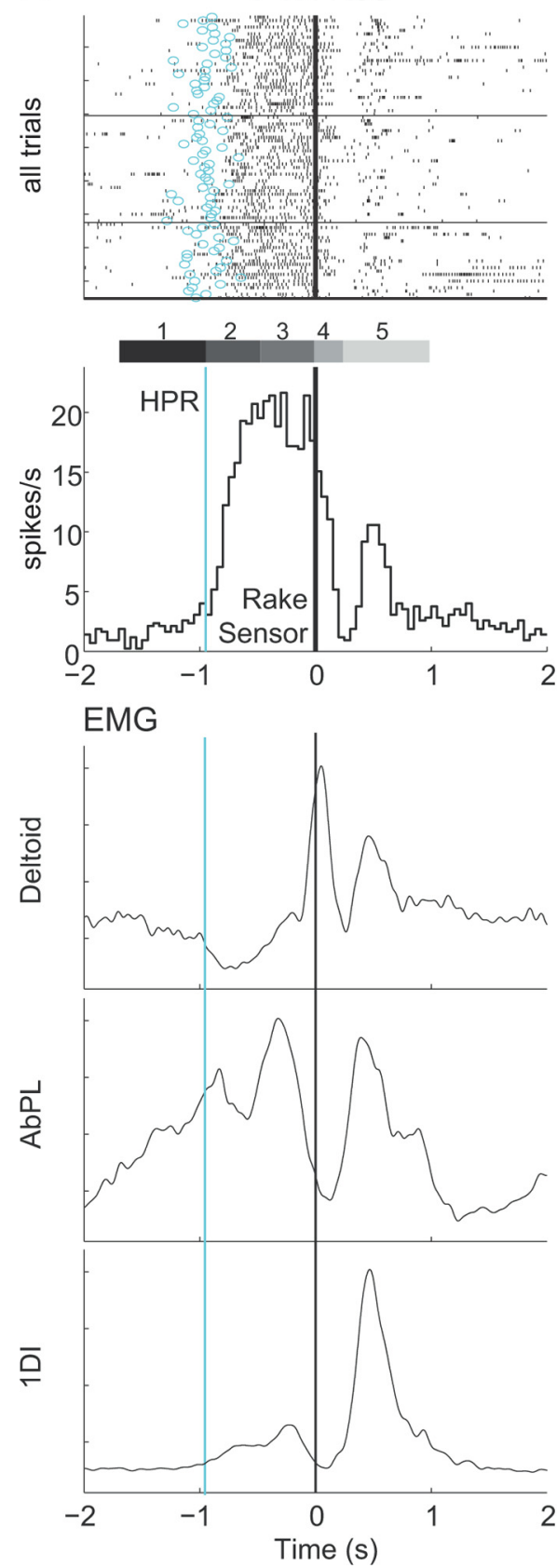

B

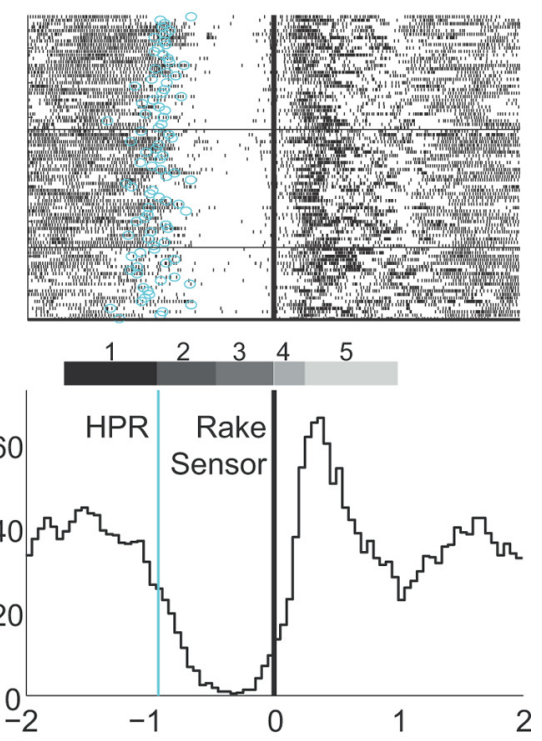

Figure 3. Two typical patterns of PTN activity during the rake task. Rasters and perievent histograms show activity for two PTNs recorded in monkey M41 during the rake task [PTN R58, 85 trials $(\boldsymbol{A})$ and PTN R50, 88 trials $(\boldsymbol{B})$ ]. Data are shown for raking trials involving all three targets and referenced to the moment the rake crossed a target sensor (time 0 with vertical line). The circles on the left side of the rasters and the vertical line in the histograms indicate the moment at which the experimenter released the home pad (HPR). The approximate time course of the different periods of the task are indicated by the gray scale bar beneath the rasters (see Fig. 2). For the PTN in $\boldsymbol{A}$, discharge began when the monkey picked up the rake (period 2) and peaked during rake reach and swing (period 3). The PTN in $\boldsymbol{B}$ had a high level of baseline activity that was suppressed during rake pickup (period 2) and stopped firing during rake reach (3), then followed by a burst of activity in the later stages of the rake return and food pickup (periods 4 and 5). In the rasters, trials have been reordered according to target (top, right target; middle, center target; and bottom, right target; horizontal black line indicates change of target location). PTN R58 showed no position sensitivity ( $p=0.41$ ), whereas R50 did $(p=0.013)$. Averaged rectified EMG (taken from the same trials) for deltoid, AbPL, and 1DI, normalized to the respective peak for

stimulus (biphasic pulse; each phase, $0.2 \mathrm{~ms}$ ) was applied to the pyramidal tract electrodes, and each electrode advanced until a PTN was detected. PTNs were identified by the invariant latency (jitter $<0.1 \mathrm{~ms}$ ) of its antidromic response to the pyramidal tract shock and by a collision test (Kraskov et al., 2009). We then recorded from each PTN during both 
A

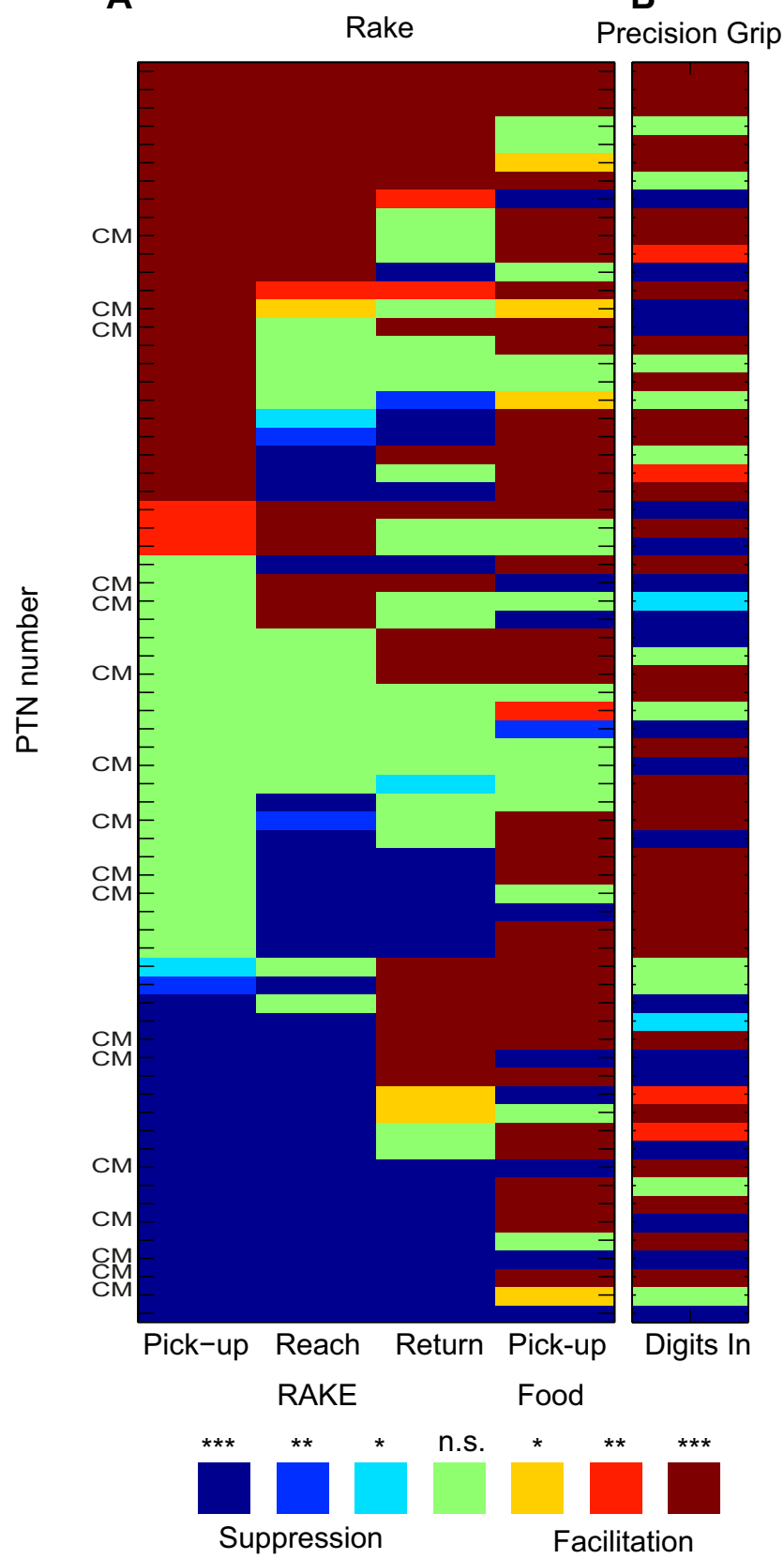

Figure 4. Modulation of population of PTNs during the rake task. The vertical columns in $\boldsymbol{A}$ indicate the four rake task periods (pickup, reach and swing, return, and food pickup) in which a post hoc test (see Materials and Methods) revealed a significant modulation in the discharge of each PTN. Each horizontal line and tick marks indicates the results from the 69 PTNs tested. The color scale for significance of increases and decreases is shown on the right. Yellow to red indicate a positive significant effect (facilitation), and light blue to dark blue indicate a negative significant effect (suppression). Green, Nonsignificant change. Note the large number of PTNs that were suppressed during the rake task. $\ln \boldsymbol{B}$, the analysis for the same set of 69 PTNs during the digits-in period of the precision grip (PG) task is shown; PTNs are shown in the same order as in $A .{ }^{*} p<0.05 ;{ }^{* *} p<$ $0.01 ;{ }^{* * *} p<0.001$.

the performance of the rake and precision grip tasks; after blocks of trials had been completed on the rake task, the rake table was carefully removed and the precision grip manipulandum was placed in front of the monkey. The antidromic responses of the PTN were checked regularly (see Results).
Table 1. Proportion of PTNs

\begin{tabular}{lllll}
\hline & $\begin{array}{l}\text { Rake pickup, } \\
\text { period 2 }\end{array}$ & $\begin{array}{l}\text { Reach and swing, } \\
\text { period 3 }\end{array}$ & $\begin{array}{l}\text { Return, } \\
\text { period 4 }\end{array}$ & $\begin{array}{l}\text { Food pickup, } \\
\text { period 5 }\end{array}$ \\
\hline Facilitation & $27(39)$ & $20(29)$ & $25(36)$ & $43(62)$ \\
Suppression & $20(29)$ & $33(48)$ & $22(32)$ & $10(14)$ \\
Total modulated & $47(68)$ & $53(77)$ & $47(68)$ & $53(76)$ \\
MPI & $14(20)$ & $10(14.5)$ & $10(14.5)$ & $35(51)$ \\
MPS & $11(16)$ & $29(42)$ & $15(22)$ & $14(20)$ \\
\hline
\end{tabular}

Top, Proportion of PTNs showing significant modulation during different periods of the rake task, with percentages in parentheses; bottom, proportion of PTNs showing their maximum (MPI) or minimum (MPS) relative firing rate during different periods of the rake task.

\section{Analyses}

Spike discrimination. Spikes from PTNs were discriminated and identified online, during the experiment. After the experiment, all spike waveforms were reanalyzed and sorted into different classes attributed to separate single neurons using the clustering method based on the "Wave_clus" software (Quian Quiroga et al., 2004), which runs under Matlab. Criteria for discrimination of spikes were the same as those used by Kraskov et al. (2009).

Statistical analyses of firing rate. We rejected trials that had either too long or too short an interval between the home-pad release (HPR) signal and rake sensor signal. All trials that were outside the three interquartile distance from the median were rejected. This resulted in rejection of $\sim 7 \%$ of trials. Perievent histograms of spike activity ( $150 \mathrm{~ms}$ bin width, with a $50 \mathrm{~ms}$ sliding window) were constructed with reference to different task events. The rake task was separated into a baseline period and four different task periods (see Figs. 1C, 2 and Results). The food pickup period (period 5) was also included in the analysis. A two-way ANOVA was performed on average firing rate per task period as the dependent variable and task period (five) and position of food on the raking table (three) as fixed factors for each PTN. Post hoc $t$ test tests with a Bonferroni's correction were used to identify any period that was significantly different from the baseline period. The depth of modulation of firing rate for each task period was estimated as the mean percentage increase (MPI) from the baseline rate for each $150 \mathrm{~ms}$ bin, and the period with the highest MPI was determined. Similarly, for neurons exhibiting a reduction in firing rate during the task, the mean percentage suppression (MPS) was calculated for each $150 \mathrm{~ms}$ bin, and the period with the lowest MPS was identified. To compare firing rate modulation in the rake task with that in the precision grip task, for each task period, the $150 \mathrm{~ms}$ bin with the average highest mean firing rate was identified and compared with the baseline period; for technical reasons, the baseline period from the rake task was used for estimating firing rate modulation for both tasks.

Cross-correlation functions. We used the methods described by Holdefer and Miller (2002) and Jackson et al. (2007) to compute the crosscorrelation functions (CCFs) for each of the PTNs for which $>2000$ spikes were available. The EMGs were rectified and low-pass filtered (20 $\mathrm{Hz}$, Butterworth second order) to extract the modulation envelop. Average spike count in non-overlapping $10 \mathrm{~ms}$ bins and average EMG in the same bin were used to compile CCFs for a period $1 \mathrm{~s}$ before and after spike discharge (see Fig. $8 A$ ). We also computed the correlation between CCFs for spike and EMG data recorded during rake versus precision grip tasks (indicated by the term "rr").

Spike-triggered averaging (STA) for each PTN was performed using all discriminated PTN spikes and EMGs recorded during both the rake and precision grip task tasks. The identification of CM cells used the criteria used in previous studies from this laboratory (Lemon et al., 1986; Baker and Lemon, 1995; Bennett and Lemon, 1996). The EMG from each muscle recorded simultaneously with the PTN was full-wave rectified and averaged with respect to spike discharge over a period $-20 \mathrm{~ms}$ before and $40 \mathrm{~ms}$ after spike discharge. Averages were compiled with a minimum of 2000 spikes.

\section{Histology}

At the end of the experiment, each monkey was killed by an overdose of pentobarbitone ( $50 \mathrm{mg} / \mathrm{kg}$, i.p., Euthanal; Rhone Merieux) and perfused through the heart. The cortex and brainstem were first photographed, 
removed, and sectioned on a freezing microtome. Histological analysis confirmed the location of the implanted electrode tips within the pyramidal tract (Kraskov et al., 2009).

\section{Results}

\section{Performance on the rake task}

Monkeys typically completed $\sim 300$ trials on the rake task in a recording session, with each trial lasting $\sim 3$ s. The monkey gripped the shaft of the rake in the palm of its left hand, curling the thumb and fingers around the shaft (Fig. $1 A$ ). Figure $1 B$ shows the trajectories of the monkey's hand while raking from the three different targets in a single session. Reaches to the right target were therefore directed medially, whereas those to the left target were directed laterally. The trajectory was quite variable from trial to trial and covered a large proportion of the raking table. Each trial was separated into five different periods, as indicated in Figure 1C: baseline (period 1), rake pick-up (period 2), reach and swing of the rake head to place it behind the food reward (period 3), a pulling action to return the rake and reward toward the monkey (period 4), and release of the rake and pickup of the food reward (period 5).

These periods are shown again in Figure 2, together with EMG activity from eight different hand and arm muscles (M43), averaged over 30 trials of raking from the right target and aligned to the moment the rake was pulled across the right sensor (time 0 ). For these 30 trials, the mean \pm SD interval between HPR and the sensor signal was $710 \pm 290 \mathrm{~ms}$. Period 1 ("baseline") lasted for the $750 \mathrm{~ms}$ leading up to the release of the home pad by the experimenter (HPR; Fig. 1C, Experimenter action). During this period, the monkey sat quietly with its left hand close to the rake that lay on the table (Fig. $1 B$, dashed outline) and its right hand on the block (Fig. 1B, B). Period 2 ("Rake pick-up") began when the experimenter released the home pad and uncovered the reward. This period was defined as occupying the first half of the interval between HPR and the sensor signal and lasted $\sim 350-500$ ms. Period 3 ("Reach \& swing") was defined as taking up the second half of this interval. Period 4 ("Return, rake crosses sensor") lasted from the moment the rake crossed the sensor to 250 ms later. Period 5 ("Food pick-up"), the last period, lasted from 250 to $1000 \mathrm{~ms}$ after the rake crossed the sensor, during which time the monkey released the rake and grasped the raked reward. The duration of these periods were chosen on the basis of average values and were selected after detailed examination of the video and EMG records of the monkeys' performance; there was considerable trial-by-trial variation in the speed and direction of raking movements within a session (Fig. 1B). Monkeys generally raked fastest for rewards placed at the left sensor and slowest for those at the right sensor (see below).

\section{EMG activity during the rake task}

Figure 2 shows rectified EMGs from different muscles, which have been smoothed and averaged with reference to the sensor signal. As expected, proximal arm muscles (biceps and anterior deltoid) were active during the reaching and pulling phases of the task, but it is clear that distal muscles (thenar, AbPL) were also active during this complex task. There were marked bursts of activity in all muscles, for example, in thenar and in the wrist extensor ECR-L when the monkey first picked up the rake (period 2) and extended its arm to place the rake beyond the target (period 3). Wrist flexor (FCR) and extensor (ECU) muscles were active as the monkey withdrew the rake (period 4). There were additional bursts of activity in AbPL, thenar, and EDC as the monkey released the rake and picked up the food reward (period
5) and a late burst in biceps as it brought the food reward to its mouth. These averages conceal considerable trial-by-trial variation in EMG activity in this relatively unconstrained task; nevertheless, it is clear that the rake task is associated with a temporally fractionated pattern of activity in distal muscles, such as AbPL and thenar.

\section{Activity of M1 PTNs during the rake task}

A total of 69 PTNs were recorded within M1: 27 in monkey M43 (16 recording sessions, PTNs E1-E27) and 42 in monkey M41 (18 sessions; PTNs R28-R69). PTNs were recorded for at least 120 trials (i.e., 40 for each target, presented in a pseudorandom order). Most of these PTNs were recorded in tracks made just anterior to the central sulcus (Fig. 1D; Kraskov et al., 2011) at 17-19 $\mathrm{mm}$ from the midline and at depths between 1 and $5.2 \mathrm{~mm}$ from the surface: many of these PTNs would therefore have been located in the anterior bank of the sulcus. Antidromic latencies varied from 0.6 to $6.0 \mathrm{~ms}$ (median, $1.2 \mathrm{~ms}$ ). ICMS-evoked motor responses were found at 100\% (monkey M41) and 77\% (M43) of M1 sites at which PTNs were recorded. These ICMS effects were obtained with intensities between 7 and $22 \mu \mathrm{A}$ and were specific to the digits at 91 and $62 \%$ sites in M41 and M43, respectively.

Figure $3 A$ shows an example of M1 PTN (R58) activity during the rake task. Again, all data have been aligned to the point at which the rake crossed the sensor (time 0). Spike rasters are shown for trials involving all three targets. For these trials, the mean interval between HPR and the monkey pulling the rake across the sensor was $950 \pm 130 \mathrm{~ms}$, which was typical for monkey M41. This PTN had little or no resting discharge; it began to fire just after the home pad was released by the experimenter (blue circles superimposed on raster plots), which was the cue for the monkey to pick up the rake. Discharge continued as the monkey reached the target (period 3) and pulled the rake back over the sensor (period 4), after which it fell silent. There was a much smaller burst of activity during food pickup (period 5).

A second example is shown in Figure $3 B$ (PTN R50). In this case, there was a relatively high and stable discharge during the baseline period of $\sim 40$ spikes/s. When the monkey grasped the rake, there was a striking decrease in activity, and PTN discharge was completely absent until just before the rake was pulled over the sensor (time 0). A burst of activity ensued as the monkey released the rake and picked up the food reward (period 5).

To summarize the activity in the population of 69 PTNs sampled in this study, a two-way ANOVA, for task period and reward location, was performed. Post hoc tests, with a Bonferroni's correction, revealed the periods $(2-5)$ in which a PTN exhibited modulation of its discharge when compared with baseline, and this is shown in Figure $4 A$. PTN activity was either significantly increased (yellow, $p<0.05$; light red, $p<0.01$; dark red, $p<$ 0.001 ) or decreased (light blue, $p<0.05$; blue, $p<0.01$; dark blue, $p<0.001)$ compared with baseline values; green indicates nonsignificant changes. Results for the 69 PTNs have been ordered according to presence of facilitation in all three rake periods (top) through to suppression in all three periods (bottom), with those PTNs showing no significant modulation in the middle. The data are summarized in Table 1 (top).

Compared with baseline, most PTNs (64 of 69, 93\%) showed significant modulation in at least one of the three periods involving use of the rake. In all, 68\% PTNs showed significant modulation in the rake pickup period, $77 \%$ during reach and swing, and $68 \%$ during return. For the three periods together, between 29 and $39 \%$ of the PTNs sampled showed significant facilitation. 


\section{Effect of rake position}

A

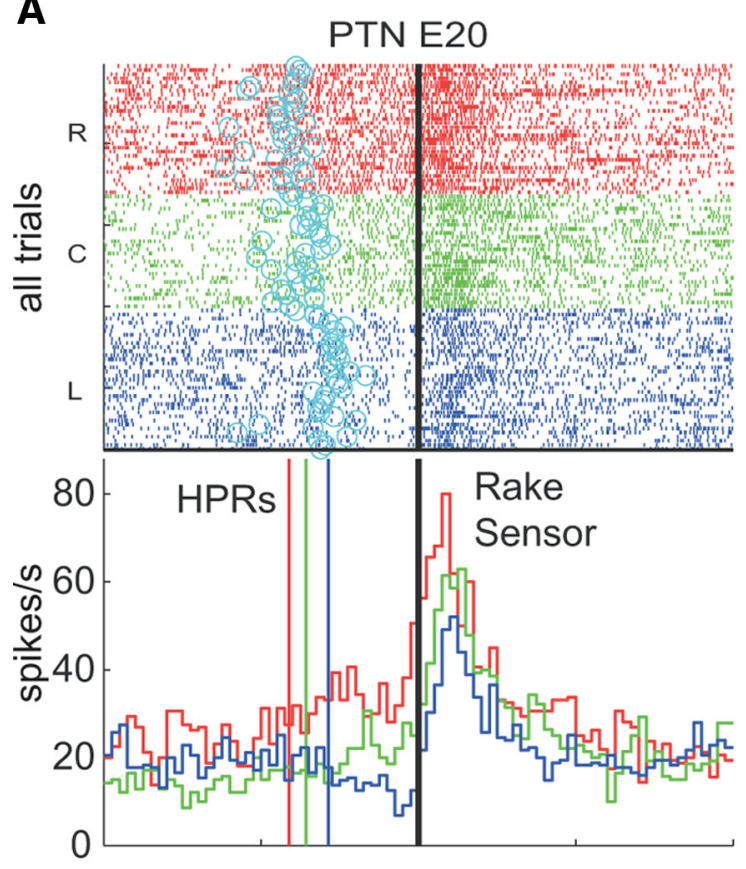

B

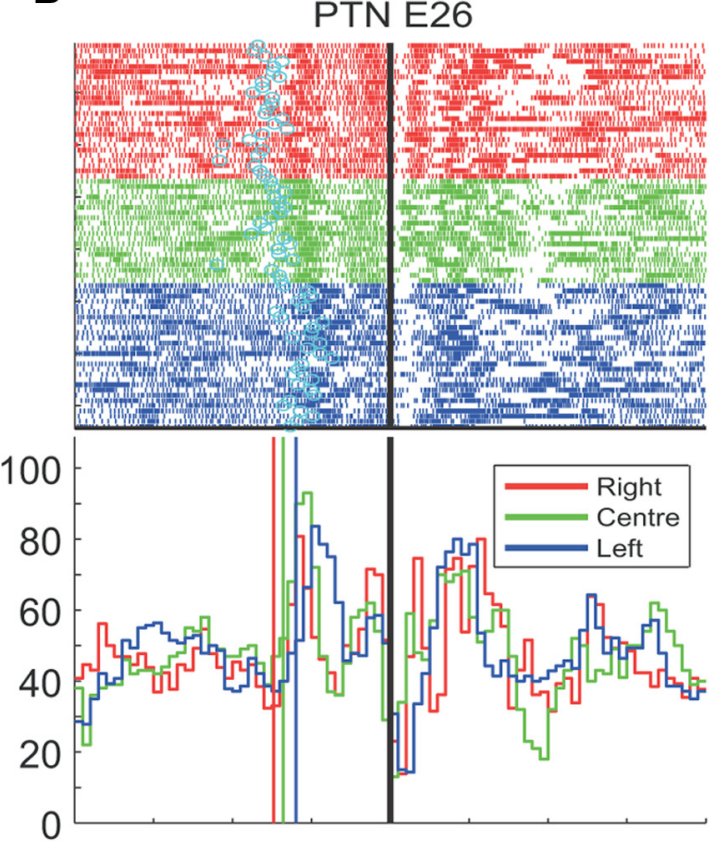

\section{EMG}
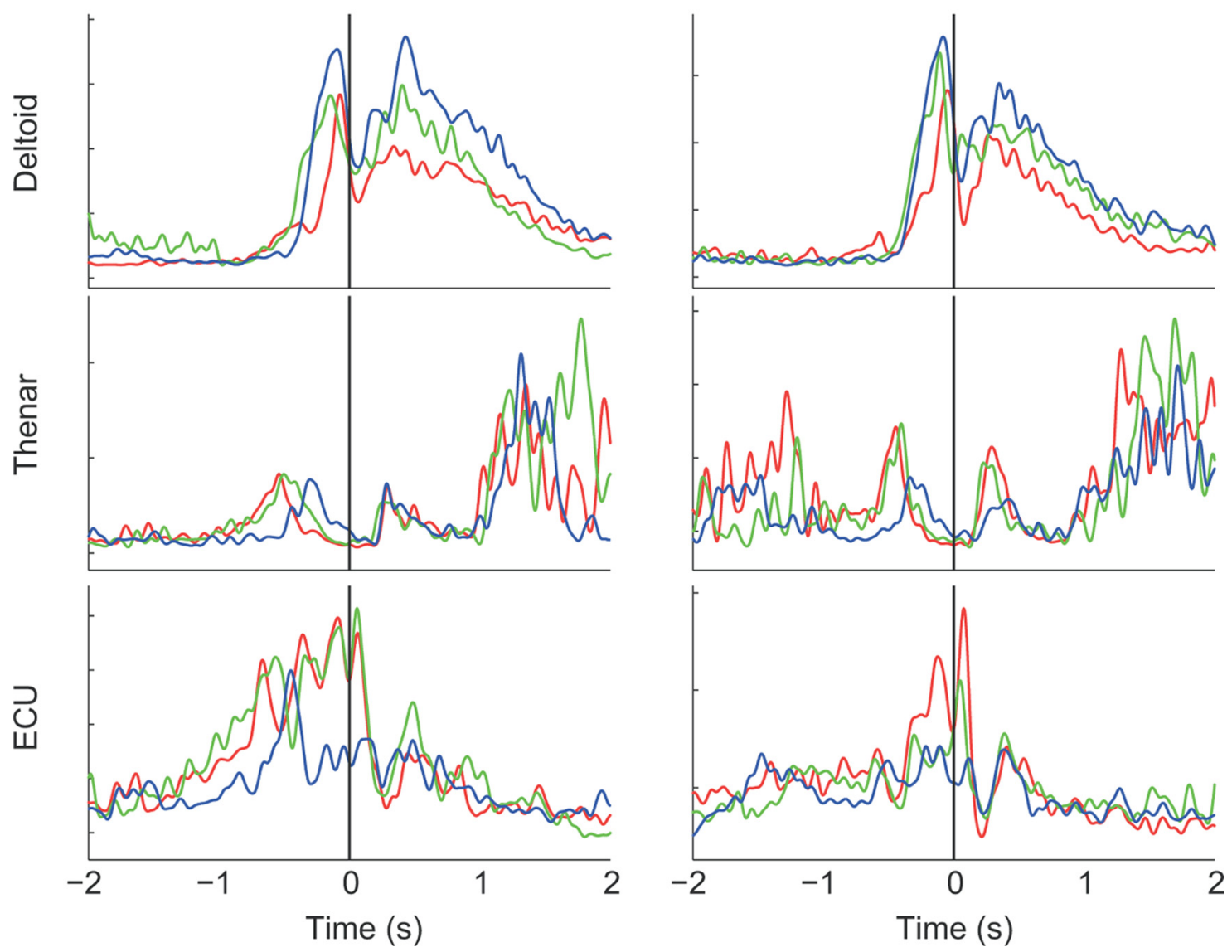

Figure 5. Effect of target position on raking activity. A shows an example of a PTN recorded in monkey M43 (E20) during the rake task that showed a clear variation according to the position from which the monkey raked its reward. Layout is the same as in Figure 3 . The color code refers to the target sensor at which the food was placed: red and blue, respectively, for the sensor to the right and left of the monkey and green for the central sensor. Rasters ( $\sim 30$ trials for each position) are referenced to the sensor signal (time 0$)$. In the histograms below, the average firing rates are also plotted with the same color scheme. Note that there was a consistent position-dependent variation in the time between HPR and sensor signal (fastest for left target, slowest for right). The PTN in $\boldsymbol{B}$ (E26) showed very little variation in firing rate with food position ( $\sim 25$ trials per position). Note that normalized EMG activity from deltoid and ECU exhibited clear position-related differences. 


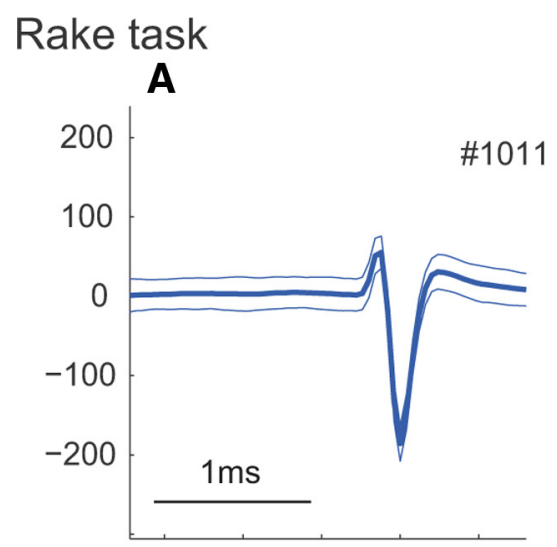

\section{Precision Grip}
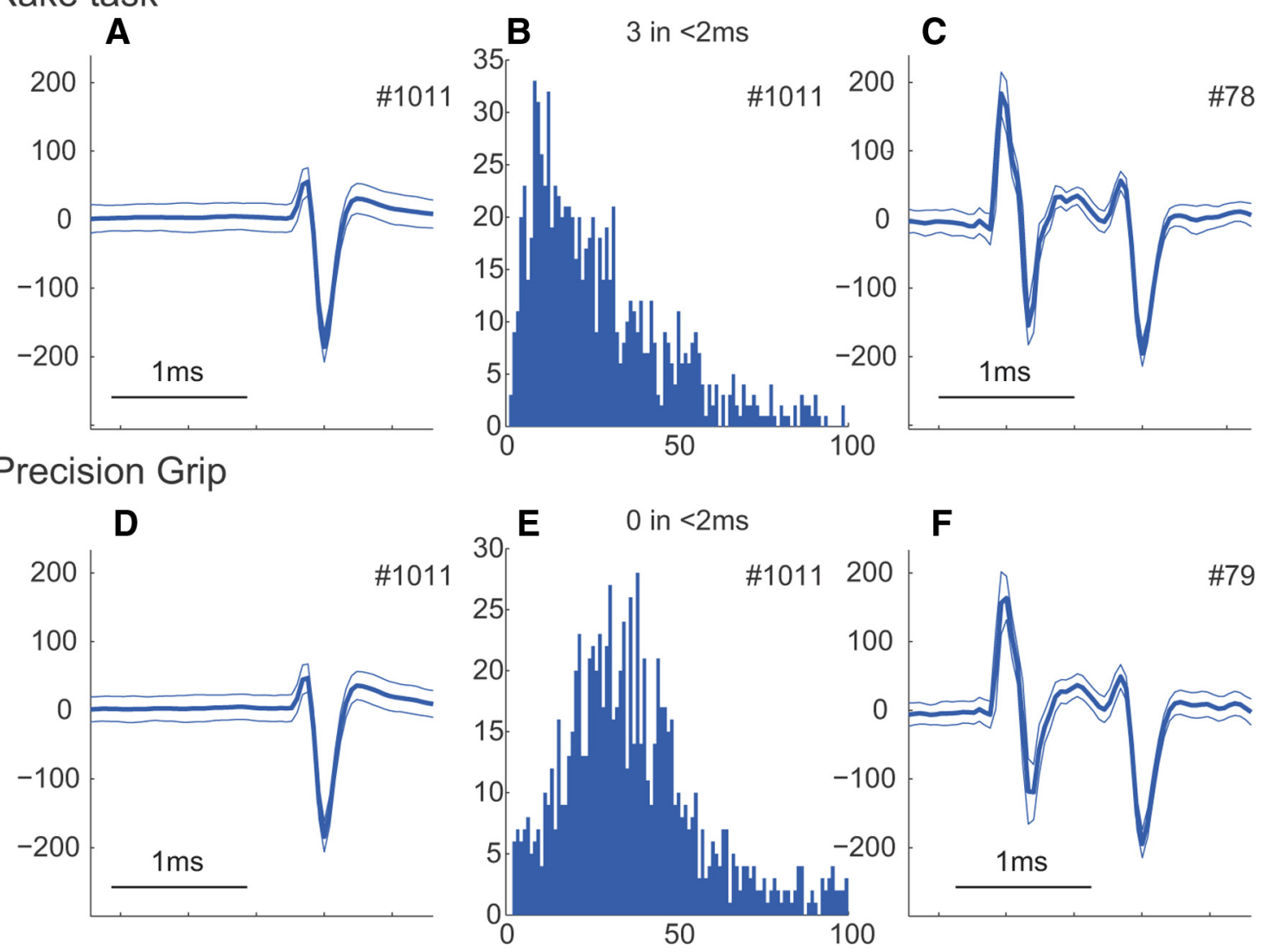

Figure 6. Confirmation that the same PTN was recorded during both rake and precision grip tasks. Spike discrimination $(\boldsymbol{A}, \boldsymbol{D})$, interspike interval $(\boldsymbol{B}, \boldsymbol{E})$, and antidromic responses $(\boldsymbol{C}, \boldsymbol{F})$ from a PTN are shown. The amplitude and shape of the spike was constant during both the rake task $(\boldsymbol{A})$ and precision grip task $(\boldsymbol{D})$; average \pm SEM of spike shape for 1011 spikes are shown. The interspike intervals of these 1011 spikes from the PTN $(\boldsymbol{B}, \boldsymbol{E})$ confirmed the quality of the clustering by demonstrating the almost total absence of any unphysiologically short intervals ( $<2 \mathrm{~ms})$. The PTN fired at higher frequencies during the rake versus precision grip tasks. The PTN responded antidromically at short latency $(0.9 \mathrm{~ms})$ after the pyramidal tract stimulus (artifact to left of records in $\boldsymbol{C}$ and $\boldsymbol{F}$ : averages of responses to 78 and 79 stimuli, respectively). Antidromic responses were identical before the rake task $(\boldsymbol{C})$ and before the precision grip task $(\boldsymbol{F})$.

However, as Figure $4 A$ and Table 1 (top) show, the overall pattern of activity was rather heterogeneous. In particular, it was striking that so many PTNs showed significantly suppressed activity during rake use (29-48\%, depending on period); in many cases, these PTNs ceased to fire altogether (Fig. 3B). There were nine PTNs that showed suppression in all three rake periods and, of these, five were facilitated during food pickup, three were suppressed, and one was not significant. During the initial "digits-in" period of the precision grip task, four of these PTNs showed increased discharge.

In contrast to this pattern of suppression, the majority of PTNs (43 of 69; 62\%) showed increased discharge during food pickup at the end of the trial (Fig. $4 A$, last column). Of these 43 PTNs, 32 were significantly modulated during rake pickup: 19 showed facilitation, and 13 showed suppression. There were nine PTNs that showed modulation during rake pickup but not during food pickup.

The period in which PTNs showed their highest increase in firing rate relative to baseline (maximum MPI; see Materials and Methods) is given in Table 1 (bottom). Although $20 \%$ of PTNs had their MPI during rake pickup, $51 \%$ showed this during food pickup. Many PTNs (42\%) showed maximum suppression (MPS) during the reach period.

\section{Effect of reward position on PTN activity}

In an attempt to distinguish PTNs whose activity was better related to the distal hand movements involved in grasping and holding the rake from those PTNs with activity associated with extending the rake to reach and retrieve rewards, we examined the activity of PTNs when the food reward was placed at different positions on the rake table (Fig. $1 B$ ). Each position was equipped with a sensor. Figure $5 \mathrm{~A}$ shows an example of a PTN (E20) that showed some position-dependent activity. Rasters and averages are again aligned to the point at which the rake crossed the sensor. In this session, the mean interval between HPR and the sensor signal was shortest $(590 \pm 150 \mathrm{~ms})$ for raking from the left target (blue), longest ( $870 \pm 150 \mathrm{~ms})$ for the right target (red), and intermediate $(750 \pm 130 \mathrm{~ms})$ for the central (green) target. The PTN shown was mainly active as the monkey pulled the rake and reward back from the sensor (Fig. 1C, period 4). There was greater discharge for raking from the right-hand sensor (red) and least for the left (blue), with intermediate activity for the center target (green). Differences in EMG activity for raking from the three targets were particularly striking in muscles acting at the wrist (ECU) and shoulder (deltoid) but less so in thenar muscles.

Overall, 36 PTNs (52\%) showed a main effect of food position (two-way ANOVA with five task periods and three positions as main factors, $p<0.05$ ). The remaining PTNs showed little or no position dependence. The example shown in Figure $5 B$ was particularly active for the rake pickup, but the depth of modulation in its discharge was not significantly affected by the sensor on which the food was placed $(p=0.64)$. Another such example is shown in Figure $3 A$ (R58). 
A

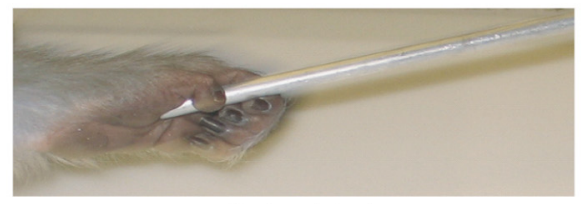

B

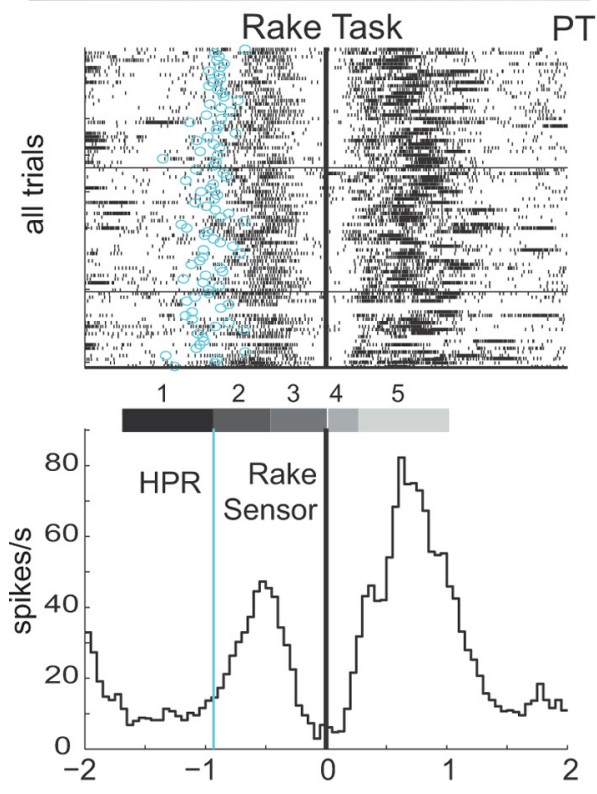

EMG

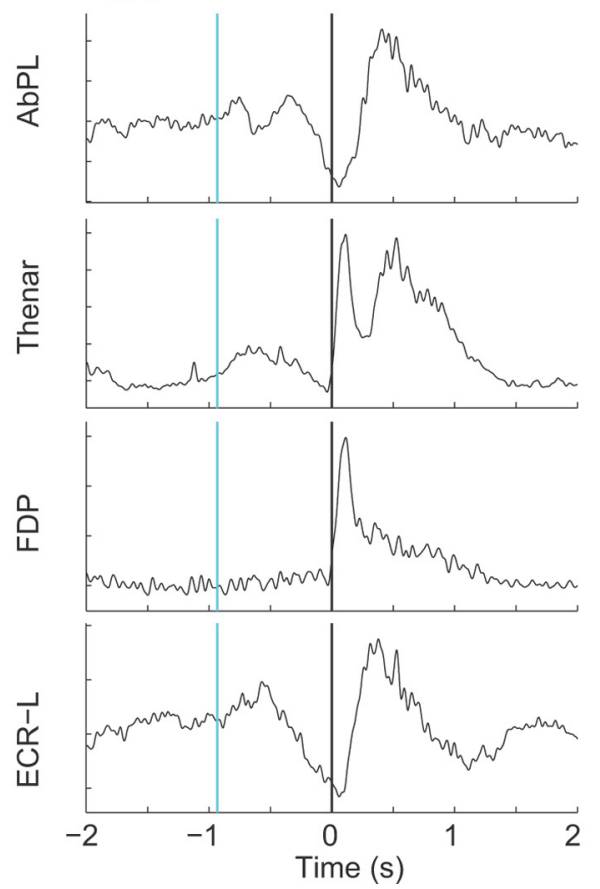

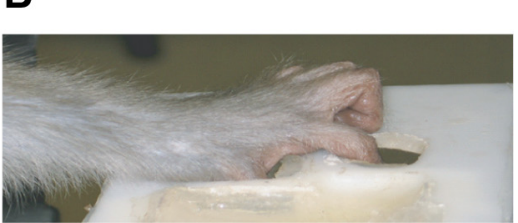
PTN R48
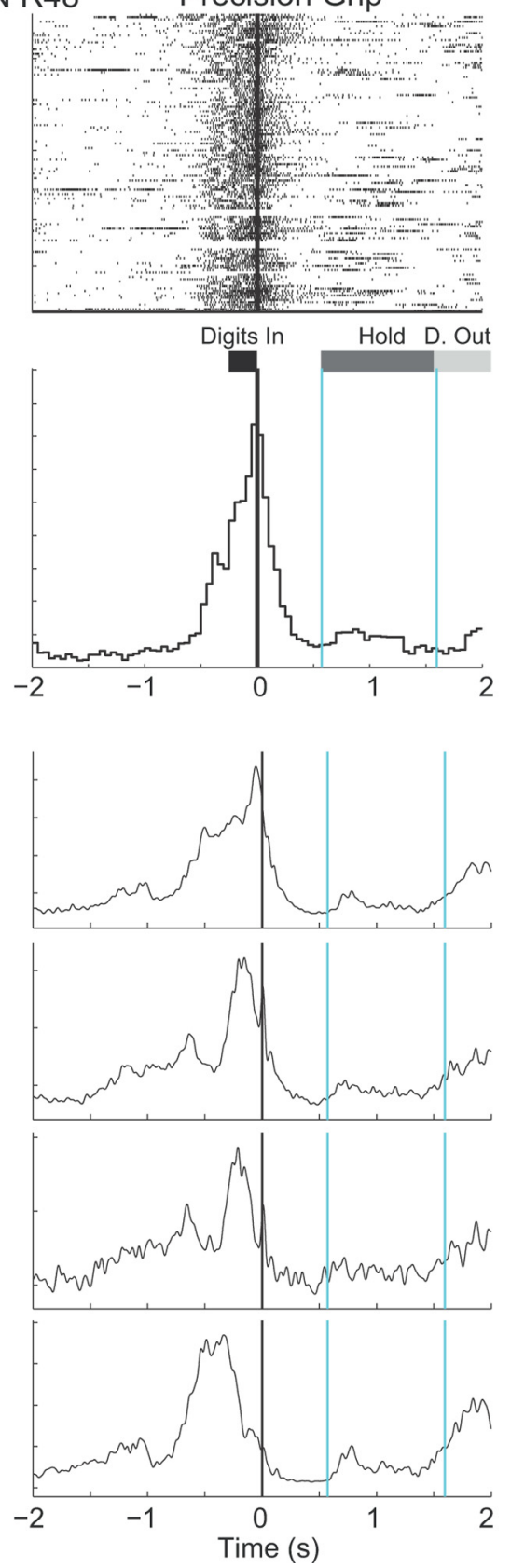

Figure 7. Comparison of PTN activity during rake and precision grip tasks. $\boldsymbol{A}$ shows the activity of a PTN (R48) during the rake task ( 85 trials). $\boldsymbol{B}$ shows the activity for this same PTN during the precision grip task (126 trials). For the rake task, the rasters are aligned to the sensor signal, and the gray scale bar shows the approximate duration of the different periods of the task (see Figs. 1, 2). For the precision grip task, they are aligned with the onset of displacement of the levers by the index finger and thumb, after they had been inserted into the manipulandum (Digits $\mathrm{In}$ ). The monkey displaced the levers into a target zone and held them there for $\sim 1 \mathrm{~s}$ (Hold), after which the monkey removed its digits (D. Out). Averaged, smoothed, and rectified EMGs from AbPL, thenar, FDP, and ECR-L muscles recorded during both tasks are shown. Normalized EMG plotted at the same scale for both tasks.

Activity in the same PTN for rake versus precision grip tasks A specific objective of this study was to investigate whether a PTN with activity strongly modulated during the rake task was also modulated during precision grip. All 69 PTNs were therefore recorded during a precision grip task (Baker et al., 2001). This task requires fractionated movements of the digits and independent positioning of spring-loaded levers by the index finger and thumb.

To ensure that the same neuron was recorded for both tasks, we carefully rechecked the antidromic identification of each PTN before and after performance of the two tasks. Figure 6 illustrates the spike discrimination of a PTN during the rake and then during the precision grip task. The shape and amplitude of the PTN spike remained unchanged across tasks. Note the difference in the distribution of interspike intervals across the tasks for this PTN, with higher frequencies during the rake task (Fig. $6 B$ ) than during the precision grip task (Fig. 6E). Figure 6, $C$ and $F$, shows the antidromic responses from the PTN (0.9 ms antidromic latency) that were identical when tested before the rake task (Fig. $6 C$ ) and after precision grip (Fig. 6F).

Figure 7 shows the activity of the same PTN (R48) for the rake task $(A)$ and precision grip task $(B)$. This PTN was particularly active for the rake pickup and showed a peak firing rate during this period of $\sim 50$ spikes/s. During the precision grip task, this PTN was strongly modulated as the monkey inserted its digits into the manipulandum and moved the levers into the target position, with a peak rate of $\sim 70$ spikes/s. Figure 7 also presents averaged EMG data from the same set of muscles for the two tasks; muscles acting on the digits (AbPL, thenar, and FDP) and wrist (ECR-L) were active during both tasks.

\section{PTN activity during precision grip}

We calculated the proportion of PTNs active for three different precision grip task periods: period 1 digits-in was for the 250 ms up to the first detectable movement of the manipulandum levers and reflected the dynamic phase during which the monkey brought its thumb and index finger into position to displace the two levers. Period 2 was the "hold" period, which lasted for $1 \mathrm{~s}$ after the monkey began to hold the levers within the set displacement limits (5-9 $\mathrm{mm}$ from the start position). This "hold-start" signal was defined as the moment when both levers were stabilized (close to zero lever velocity) within the target window. Period 3 "digits-out" lasted for the $500 \mathrm{~ms}$ after the end of the hold period (i.e., 1000-1500 ms after the hold start). Values were calculated relative to the baseline firing rate during the rake task (there was no equivalent baseline period in the precision grip task). 
Table 2. Activity of PTNs during rake task (pickup period) versus precision grip task (digits in period)

\begin{tabular}{llll}
\hline & $\begin{array}{l}\text { PTNs with } \\
\text { facilitation in } \\
\text { rake pickup (27) }\end{array}$ & $\begin{array}{l}\text { PTNs with } \\
\text { suppression in rake } \\
\text { pickup (20) }\end{array}$ & $\begin{array}{l}\text { PTNs with no } \\
\text { significance for } \\
\text { rake pickup (22) }\end{array}$ \\
\hline Digits in facilitation & $16(59)$ & $8(40)$ & $13(59)$ \\
Digits in suppression & $6(22)$ & $8(40)$ & $7(32)$ \\
Digits in not significant group & $5(19)$ & $4(20)$ & $2(9)$
\end{tabular}

Percentages are shown in parentheses.

Most PTNs (67 of 69, 97\%) showed significant modulation in at least one of the three precision grip periods. In all, 58 PTNs $(84 \%)$ showed significant modulation during the digits-in period, $53(77 \%)$ during hold, and 57 (83\%) during digits-out. The majority $(67 \%)$ of PTNs recorded during the precision grip task showed their maximum MPI during the digits-in period. Fewer PTNs (23\%) had their maximum MPI in the digits-out period and even fewer $(10 \%)$ in the hold period. The period that contained the lowest firing rate relative to baseline (MPS) was more evenly distributed with 36,36 , and $28 \%$ of cells in the digits-in, hold, and digits-out periods, respectively.

Comparison of PTN activity in rake versus precision grip tasks Of the 69 PTNs tested, 62 (90\%) showed significant modulation for both tasks. We decided to focus on the comparison between the rake pickup (period 2; Figs. 1, 2) and the digits-in period of the precision grip task. We compared the data in the leftmost column in Figure $4 A$ (rake pickup) with that in Figure $4 B$ (digitsin). The data have been plotted using the same color code, and PTNs are shown in the same order in Figure 4, $A$ and $B$. PTNs showing significant facilitation in all three periods of rake use are at the top and those with suppression in all three periods at the bottom, with other patterns of change in between and those with nonsignificant changes in the middle. It is clear that this ordered arrangement in Figure $4 A$ is completely lost in Figure $4 B$. Thus, although PTNs were modulated during both tasks, their pattern of activation was often different.

This point is summarized in Table 2: of the 27 PTNs whose discharge was facilitated during rake pickup, only 16 (59\%) showed increased discharge during precision grip, and seven (26\%) showed suppression. Likewise, of the 20 PTNs showing suppression during the rake task, equal numbers $(8=40 \%)$ were facilitated or suppressed during precision grip. Of the nine PTNs that were suppressed in all three rake periods, four showed facilitation in precision grip. Analysis of the 43 PTNs that were activated during food pickup after raking (Fig. $4 A$ ) showed that a similar proportion of these PTNs were facilitated $(56 \%)$ or suppressed $(23 \%)$ during the digits-in period of the precision grip task (Fig. $4 B$ ).

We also calculated the periods in which PTNs exhibited their maximum percentage increase (MPI) or suppression (MPS): PTNs showed a similar depth of modulation for the two tasks.

\section{PTN-muscle relationships during rake versus precision grip tasks}

To investigate the correlation between PTN activity and muscle activity during the two different tasks, we computed, for each task, the CCF (Holdefer and Miller, 2002; Jackson et al., 2007) for each PTN with each of 12 muscles from which EMG was simultaneously recorded. The CCF was computed for 65 of 69 PTNs for which $>2000$ spikes were available (range of 2376-31,845 spikes). In the rake task, most PTNs (50 of $65,77 \%$ ) showed a clear CCF peak ( $r>0.1$; Fig. 8, blue curves). Figure $8 A$ presents examples of the CCF analysis for three PTNs with muscles AbPL, thenar, and ECR-L in M41. In one case (R45; Fig. 8A, left), the correlograms all showed a single broad peak, centered on time 0 (spike discharge), and these were common to all three muscles ("single peak" category of McKiernan et al., 2000). The CCF for this PTN with the same muscles during the precision grip task (black curves) was rather similar, although the positive peaks were larger and broader. To compare the correlation between discharge in a given PTN and EMG activity across the two tasks, we calculated the correlation between the CCF values for rake versus precision grip: we refer to this metric as the "correlation between correlations," or rr. For PTN R45, there was a significant positive correlation of CCFs across tasks for all of the three muscles shown; rr had values of $0.86,0.68$, and 0.84 , respectively, indicating a rather similar PTN-EMG relationship across tasks.

In contrast, for R41 (Fig. 8A, middle), there was a more complex CCF for the rake task ("double peak" category of McKiernan et al., 2000) and a strikingly different CCF for precision grip (biphasic). There was a significant negative correlation between the CCFs for all three muscles ( $\mathrm{rr}=-0.52$ to -0.68 ). The final example (R32; Fig. $8 A$, right) again showed CCF effects that were clearly different between the two tasks. Figure $8 B$ summarizes the comparison of each PTN-muscle relationship (CCF) between the two tasks. In most cases, the measure rr was positive (R45) but a considerable number of PTNs showed negative values (R41). Thus, although the great majority of PTNs showed significant modulation of discharge during both rake and precision grip tasks, they could show a range of different relationships with the muscles used to perform these tasks.

\section{Some PTNs active during the rake task are CM cells}

We investigated whether PTNs that showed modulation in their discharge during the rake task could also be identified as CM cells, because this would provide direct evidence of the involvement of the CM system in tool use. A total of 65 PTNs were tested for which STAs with $>2000$ spikes were available. Of these 65 PTNs, 17 (26\%) were identified as CM cells by the presence of clear postspike facilitation (PSF) in the STA. A total of 35 PSF effects were found from these 17 cells, and, of these, 25 (71\%) were in muscles acting on the digits.

Four STAs from two PTNs are shown in Figure 9. Spikes from PTN R48 produced a clear PSF in both thenar and FDP EMG (Fig. 9A). The PSF was present in averages compiled from data recorded during both the rake task (12,168 spikes; blue) and the precision grip (7225 spikes; black). The activity of this PTN is shown in Figure 7. PTN R50 (Fig. 9B) showed a PSF in EMGs from ECR-L and AbPL; these were relatively larger in STAs from the rake task versus precision grip. Interestingly, this PTN (rasters shown in Fig. 3B) was one of those that showed suppressed activity during rake pickup; its discharge pattern followed closely the activity of the AbPL target muscle.

All but one of the 17 identified CM cells were significantly modulated during at least one period of the rake task (Fig. $4 \mathrm{~A}$ ); three showed facilitation of discharge during rake pickup, and seven were suppressed during this period. PSF effects produced by these CM cells were stable across tasks: of the 35 effects, 26 were clearly present in averages compiled from data recorded in both rake and precision grip tasks (compare with Fig. 9). Six PSFs were detectable only in the rake data and three only in the precision grip data. As might be expected, most CM cells had generally positive correlations with their target muscles, as revealed by CCF analysis: this was the case for 21 of 26 digit muscles showing PSF (McKiernan et al., 2000). In some cases, the CCF effects were complex (see R41 in Fig. 8A, which is a $\mathrm{CM}$ cell), and CM cells, just as other PTNs, could show different relationships with their target muscles across tasks. 
A

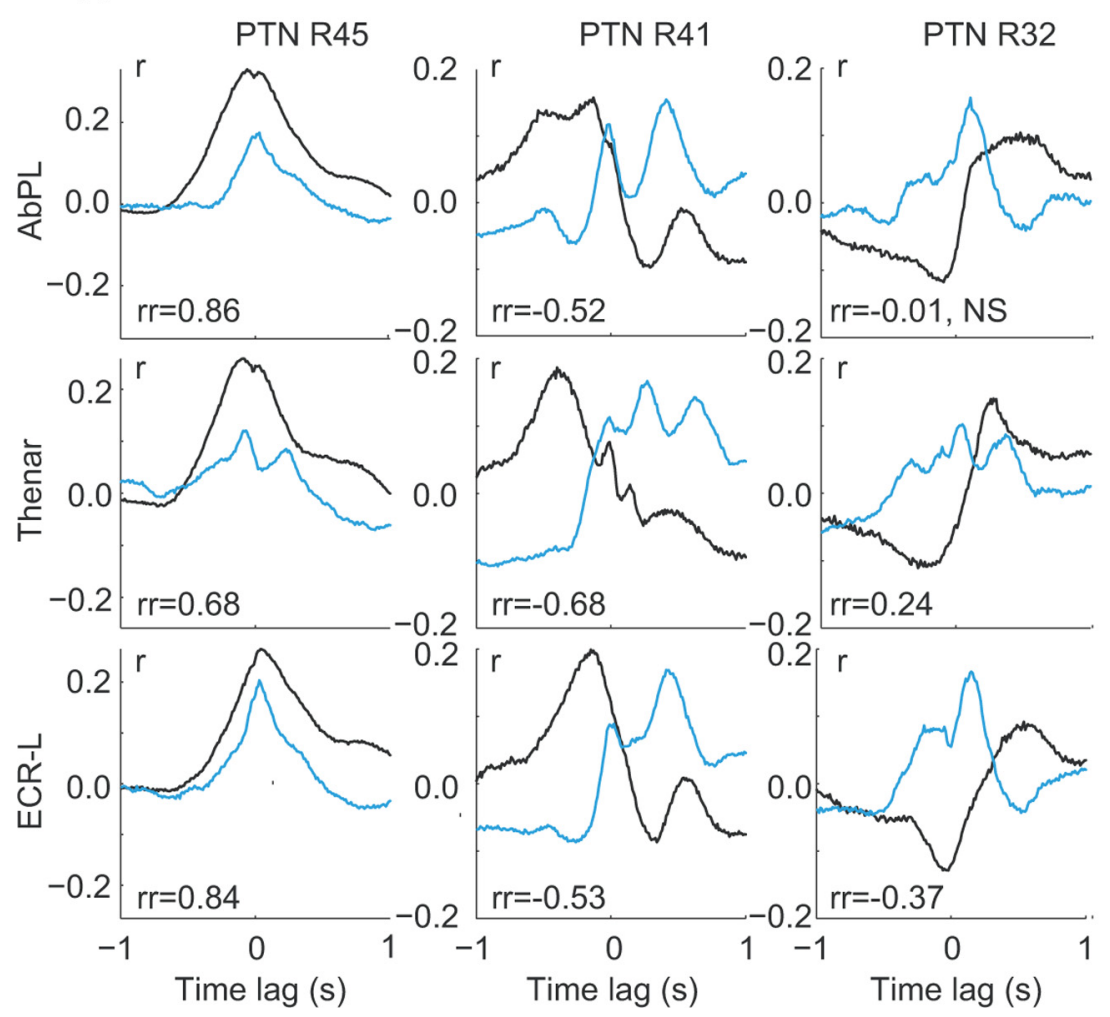

B rr, Distribution
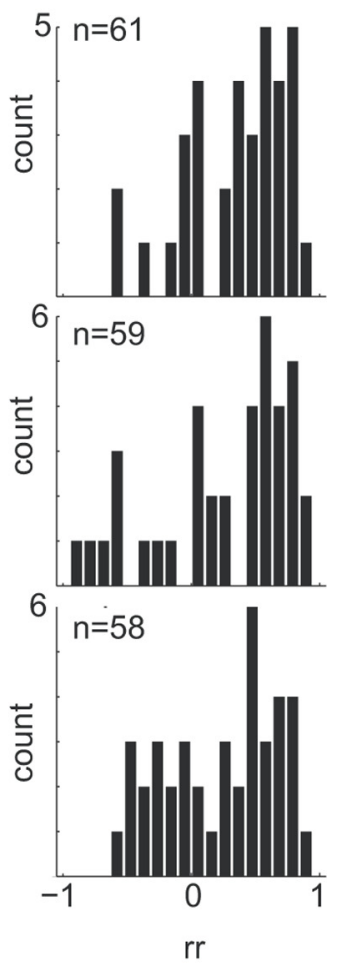

Figure 8. PTN muscle activity during rake and precision grip tasks. A, CCFs for spikes from three PTNs (R45, R41, and R32) with rectified EMGs recorded from AbPL, thenar, and ECR-L muscles. The correlation coefficient $r$ is plotted against time relative to PTN discharge (time 0 ) with a resolution of 10 ms bins. Correlations are plotted for both the rake task (blue) and precision grip task (black). The CCFs for PTN R45 during the two tasks were positively correlated (all $r r>0.6, p<0.05$ ) in all three muscles. PTNR41 showed contrasting patterns of CCF for rake and precision grip, and the CCFs were negatively correlated (all $r r<-0.5$, $p<0.05$ ), whereas mixed effects were present for PTN R32. Numbers of spikes contributing to each CCF: R45, rake 15,011 and precision grip, 10,186; R41, rake 20,595 and precision grip 7274; R32, rake 5383 and precision grip 5255. $\boldsymbol{B}$, The distribution of correlation coefficients ( $r$ ) between the rake and precision grip CCFs for all PTNs in which at least one of the CCFs was $>0.1$ are shown ( $n$ is the number of PTN-muscle pairs tested).

\section{Discussion}

The rake task has been the subject of a number of previous studies of tool use by captive Japanese macaques (Iriki et al., 1996) and Rhesus macaques (Warden et al., 1940; Shurcliff et al., 1971). We have demonstrated that $90 \%$ of PTNs recorded in the hand area of macaque M1 showed significant modulation of their discharge during the use of this simple tool. Interestingly, almost all of the PTNs modulated their activity for both the rake task and for precision grip, confirming that PTNs whose discharge is associated with independent movement of the digits are also recruited during use of a tool. A significant proportion of these PTNs were identified as CM cells influencing digit muscles and therefore shows for the first time that the CM system is involved in tool use.

\section{EMG activity during rake and precision grip tasks}

The precision grip task requires independent control of the index finger and thumb and has been used in many previous studies for identifying CM effects in the macaque (Bennett and Lemon, 1996; Lemon, 2008). The rake task is less constrained (for trial-by-trial variability, see Fig. $1 B$ ), and although it involves reaching and pulling actions that engage the proximal segments of the upper limb, digit and wrist control is necessary for fine manipulation of rake position and orientation of the rake within the hand to successfully retrieve the food. The interaction between proximal and distal muscular synergies is also characteristic of tool use in humans (Santello et al., 1998). Figure 2 shows that, in addition to EMG activity in proximal muscles such as deltoid and biceps, distal muscles (thenar, AbPL,
EDC) were active. We have demonstrated that performance on the rake task is characterized by a fractionated pattern of activity in distal muscles (Figs. 2, 3, 7A) that is presumably required to position the different digits around the shaft of the rake.

\section{Activity of PTNs and CM cells during rake and precision grip tasks}

The great majority of the PTNs sampled here had short antidromic latencies (fast-conducting axons; Fig. 6), were located in the anterior bank of the central sulcus, and were found at sites that yielded digit movements at low intensities of ICMS. In addition, a considerable proportion (26\%) of these PTNs was identified as CM cells (Fig. 9). These are all distinctive anatomical and physiological properties of the corticospinal projection to the contralateral hand (Buys et al., 1986; Lemon et al., 1986; Rathelot and Strick, 2006, 2009). The CM cells reported had most of their postspike effects in digit muscles (cf. Buys et al., 1986; McKiernan et al., 1998).

The first point to make about this sample of PTNs is that they nearly all showed well-modulated activity during the rake task (Fig. 4A). It is important to point out that they were not preselected for task-related activity but for their responses as PTNs. Nonetheless, 93\% showed significant modulation during at least one of the three main periods of the task: rake pickup, reach and swing, and rake return (periods 2-4; Fig. 4A). Forty-five percent of PTNs showed significant modulation during all of these periods. It is clear from Figure $4 A$ that different PTNs exhibited a rather heterogeneous pattern of activity across the different task 
periods, with some PTNs showing significant facilitation and suppression during different phases of rake use. However, the unconstrained nature of the task made it difficult to attribute changes in neuronal activity to any particular task component.

The second point is that careful comparison of PTN activity for the rake task versus the precision grip task showed that most PTNs (90\%) that modulated their activity during the rake task were also modulated during precision grip (Figs. 6, $7 A$ ) and that they showed a similar depth of modulation across the two tasks. This makes it likely that many of the hand area M1 PTNs that were active during the rake task were associated with movements made by the monkey's hand and digits during pickup and manipulation of the rake.

The third point is that, although PTNs were recruited in both tasks, they can show very different patterns of activity and different relationships with the muscles involved. This is evident from the comparison of Figure $4, A$ and $B$, and from the CCF data shown in Figure 8. Thus, although it might seem obvious that CM cells and other PTNs that are active for precision grip will also be active for the rake task because both are characterized by a degree of independent digit movement, the findings here confirm that the recruitment of CM cells can be highly task specific (Muir and Lemon, 1983; Bennett and Lemon, 1996; Umilta et al., 2007).We showed that $\sim 36 \%$ of the PTNs sampled showed different levels of activity for the direction of raking (Fig. $5 A$ ), which is expected because of directional tuning properties of M1 neurons (Georgopoulos et al., 1982), and might reflect PTNs primarily concerned with proximal arm muscles determining the direction of the reach. However, given the location of the recorded PTNs at sites at which ICMS yielded digit movements and the demonstration that most of the postspike effects were in digit muscles (see above), it is noteworthy that $64 \%$ of the PTNs showed no detectable position-related change [Figs. $3 A$ (R58), 5B (E26)]. This might be consistent with a class of PTNs more concerned with the distal manipulation of the rake in the hand rather than the direction of reach of the raking arm.

Why do some PTNs show suppression of activity during the rake task?

It was relatively common to find PTNs with a steady baseline firing rate that showed strong suppression of their discharge when the monkey used the rake (Figs. $3 B, 4 A$ ). Interestingly, the majority of these PTNs showed significantly increased discharge when the monkey picked up the food reward at the end of the trial (Fig. $3 B$ ). Of the $17 \mathrm{CM}$ cells identified, seven showed suppression during the rake task (Fig. 4A), whereas only one was suppressed during precision grip (Fig. $4 B$ ). The seemingly paradoxical decrease in firing rate of
STAs

A Rake task ( $n=12168)$, Precision grip $(n=7225)$

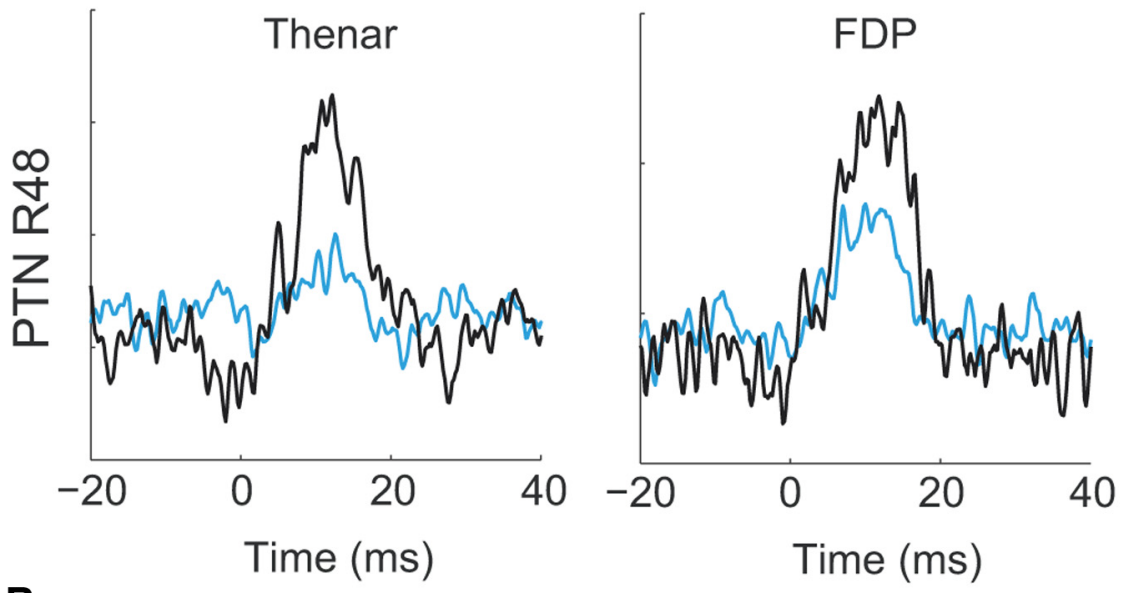

B Rake task ( $n=12688)$, Precision grip $(n=15189)$
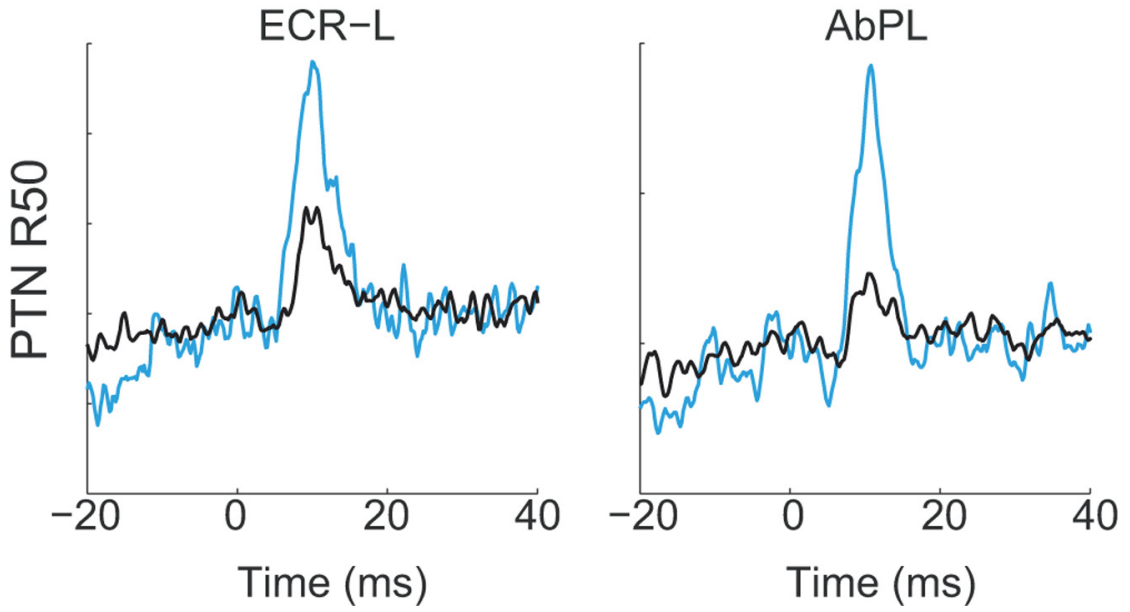

Figure 9. Evidence that PTNs active during rake task were cm cells. A, STAs showing that PTN R48 (see Fig. 7A) produced PSF of EMG from both thenar and FDP muscles. These effects were observed in STAs compiled for activity during both the rake task (blue 列 STAs have been autoscaled to the peak value of the PSF of two tasks. $B$, PSF in averages of EMG from ECR-L and AbPL muscles produced by PTN R50 (see Fig. 3B). Again, PSF was detected in both rake and precision grip data.

PTNs, especially of CM cells, is in keeping with the negative correlation between the firing rate of some M1 neurons and grip force (Smith et al., 1975) and with suppressed activity of the primary somatosensory cortex and posterior parietal neurons during grasp and manipulation (Ro et al., 2000). This may reflect inhibition of CM cells with muscle fields that are inappropriate for the particular task (Maier et al., 1993). It is also possible that a subset of CM cells might control activity in a given muscle by controlled disfacilitation, whereas another (positively correlated) subset exert control by increasing discharge rate and facilitation of target muscles. Disfacilitation might be a particularly important mechanism for controlling intrinsic hand muscles, because a recent study suggested that motoneurons of these muscles may receive relatively few inhibitory inputs from local interneuronal networks (Takei and Seki, 2010).

\section{What does M1 contribute to the rake task?}

Our results show well-modulated activity in M1 PTNs for the rake task. Because these changes of activity overlapped heavily 
with those during food grasp and precision grip (Fig. 4), the findings argue for some executive circuits that are common to use of the hand and of a tool (Jacobs et al., 2010). However, the results also suggest that there may be features of PTN activity that are characteristic of tool use, because many PTNs showed quite different relationships to muscle activity during rake use compared with food pickup or precision grip.

In an imaging study, Obayashi et al. (2002) found activity specific to the rake task in the contralateral M1 but found larger changes in the premotor cortex, intraparietal sulcus (IPS), pre-supplementary motor area, and cerebellum. The rake task can be learned by naive macaque monkeys in $<2$ weeks (Ishibashi et al., 2000; Quallo et al., 2009), possibly reflecting its natural and unconstrained character. Quallo et al. (2009) found structural changes in the cortical gray matter of monkeys learning the rake task, but these changes were in the IPS, superior temporal sulcus, and somatosensory cortex area 2 but not in motor cortex. Thus, it would appear that M1 is not specifically involved in the learning and planning of the rake task. However, it is likely that the motor cortex still provides the essential executive pathways controlling the complex interactions between digits, hand, and arm that are required for tool use. These pathways must be easily accessed by brain areas more concerned with the cognitive aspects of tool use. These might include projections from ventral premotor cortex, which can be preferentially involved in tool use (Umilta et al., 2008), and indirect projections from areas in the IPS that have been shown to be involved in tool use (Peeters et al., 2009) and in which neurons have been shown to change their properties when monkeys use a tool (Iriki et al., 1996).

\section{The corticospinal system, dexterity, and tool use}

Tool use has been described in a wide variety of different species, including cephalopods (Finn et al., 2009), birds (Hunt et al., 2001), rodents (Okanoya et al., 2008) and primates (van Schaik et al., 1999). It is therefore unlikely that this behavior is mediated by the same central nervous structures in these very different animals. However, it is the primates that exhibit the widest range of behaviors involving tools (van Schaik et al., 1999). The corticospinal system is developed to a rather variable extent in different species of nonhuman primates, and there is a correlation between the development of this system and dexterity (Lemon and Griffiths, 2005; Lemon, 2008). For example, tree shrews and marmosets have a low index of dexterity and lack CM connections. There are no reports of these species using tools in the wild; captive marmosets can be trained to use the rake, but this requires a much higher number of trials than in macaques (Yamazaki et al., 2011).

The corticospinal innervation of hand muscles in the New World capuchin monkey (Cebus appella) is well developed, and Cebus monkeys use fine finger movements to use tools (Antinucci and Visalberghi, 1986; Costello and Fragaszy, 1988; Christel and Fragaszy, 2000). In contrast, the New World squirrel monkey (Saimiri sciureus) has a poorly developed CM system (Bortoff and Strick, 1993; Nakajima et al., 2000) and it does not use the precision grip (Costello and Fragaszy, 1988), and there are to date no reports of tool use by this species.

The CM system is best developed in great apes (Leyton and Sherrington, 1917; Phillips, 1971; Kuypers, 1981) and humans (Lemon, 1993, 2008; Nakajima et al., 2000). However, there has so far been no direct evidence for the involvement of the corticospinal system and its $\mathrm{CM}$ component in tool use. The $\mathrm{CM}$ system is a putative candidate providing the capacity to grasp a tool and to manipulate it using an extensive repertoire of digit actions, for which relative independence of thumb and digit movement is a prerequisite (Porter and Lemon, 1993; Schieber and Santello, 2004). CM neurons in M1 are accessible to inputs from parietofrontal circuits that probably subserve important cognitive aspects of tool use (see above, Johnson-Frey, 2004; Iriki, 2006; Jacobs et al., 2010) and particularly to inputs from ventral premotor cortex (Shimazu et al., 2004; Davare et al., 2011; Kraskov et al., 2011), which may help to transform visual representations of targets for tool action into appropriate commands for grasping and using the tool (Umilta et al., 2007, 2008; Davare et al., 2008). The present investigation provides the first direct evidence for the involvement of the $\mathrm{CM}$ system in primate tool use and provides a description of the activity patterns involved.

Descending systems other than the CM projection may support the capacity for skilled grasp (Porter and Lemon, 1993). For example, corticospinal collaterals are known to activate C3-C4 propriospinal neurons projecting to hand motoneurons (Isa et al., 2006; Kinoshita et al., 2012). Selective inactivation of this system using "genetic dissection" showed that, in some monkeys, there was a transient impairment of precision grip, indicating a role for the C3-C4 system. However, little is known about the natural activity of these propriospinal neurons and whether this activity is appropriate for the support of skilled tasks, such as rake use. In the future, it will be interesting to compare such activity patterns with those reported here for the CM system.

\section{References}

Antinucci F, Visalberghi E (1986) Tool use in Cebus apella: a case study. Int J Primatol 7:351-363. CrossRef

Baker SN, Lemon RN (1995) A computer simulation for investigation of the contribution of presynaptic synchrony to post-spike facilitation in spike triggered averaged of rectified EMG. J Physiol 483:28P-29P.

Baker SN, Jackson A, Spinks R, Lemon RN (2001) Synchronization in monkey motor cortex during a precision grip task. I. Task-dependent modulation in single-unit synchrony. J Neurophysiol 85:869-885. Medline

Beck BB (1980) Animal tool behavior: the use and manufacture of tools by animals. New York: Garland.

Bennett KM, Lemon RN (1996) Corticomotoneuronal contribution to the fractionation of muscle activity during precision grip in the monkey. J Neurophysiol 75:1826-1842. Medline

Bortoff GA, Strick PL (1993) Corticospinal terminations in two New-World primates: further evidence that corticomotoneuronal connections provide part of the neural substrate for manual dexterity. J Neurosci 13:5105-5118. Medline

Brochier T, Spinks RL, Umilta MA, Lemon RN (2004) Patterns of muscle activity underlying object-specific grasp by the macaque monkey. J Neurophysiol 92:1770-1782. CrossRef Medline

Buys EJ, Lemon RN, Mantel GW, Muir RB (1986) Selective facilitation of different hand muscles by single corticospinal neurones in the conscious monkey. J Physiol 381:529-549. Medline

Chiang M (1967) Use of tools by wild macaque monkeys in Singapore. Nature 214:1258-1259. CrossRef Medline

Christel MI, Fragaszy D (2000) Manual function in Cebus apella. Digital mobility, preshaping, and endurance in repetitive grasping. Int J Primatol 21:697-720. CrossRef

Costello MB, Fragaszy DM (1988) Prehension in Cebus and Saimiri. 1. Grip type and hand preference. Am J Primatol 15:235-245. CrossRef

Davare M, Lemon R, Olivier E (2008) Selective modulation of interactions between ventral premotor cortex and primary motor cortex during precision grasping in humans. J Physiol 586:2735-2742. CrossRef Medline

Davare M, Kraskov A, Rothwell JC, Lemon RN (2011) Interactions between areas of the cortical grasping network. Curr Opin Neurobiol 21:565-570. Medline

Dum RP, Strick PL (1991) The origin of corticospinal projections from the premotor areas in the frontal lobe. J Neurosci 11:667-689. Medline

Finn JK, Tregenza T, Norman MD (2009) Defensive tool use in a coconutcarrying octopus. Curr Biol 19:R1069-R1070. CrossRef Medline

Georgopoulos AP, Kalaska JF, Caminiti R, Massey JT (1982) On the relations between the direction of two-dimensional arm movements and cell discharge in primate motor cortex. J Neurosci 2:1527-1537. Medline

Gumert MD, Kluck M, Malaivijitnond S (2009) The physical characteristics and usage patterns of stone axe and pounding hammers used by longtailed macaques in the Andaman Sea region of Thailand. Am J Primatol 71:594-608. CrossRef Medline 
Heffner RS, Masterton RB (1975) Variation in form of the pyramidal tract and its relationship to digital dexterity. Brain Behav Evol 12:161-200. CrossRef Medline

Hihara S, Notoya T, Tanaka M, Ichinose S, Ojima H, Obayashi S, Fujii N, Iriki A (2006) Extension of corticocortical afferents into the anterior bank of the intraparietal sulcus by tool-use training in adult monkeys. Neuropsychologia 44:2636-2646. CrossRef Medline

Holdefer RN, Miller LE (2002) Primary motor cortical neurons encode functional muscle synergies. Exp Brain Res 146:233-243. CrossRef Medline

Hunt GR, Corballis MC, Gray RD (2001) Animal behaviour: laterality in tool manufacture by crows. Nature 414:707. CrossRef Medline

Iriki A (2006) The neural origins and implications of imitation, mirror neurons and tool use. Curr Opin Neurobiol 16:660-667. CrossRef Medline

Iriki A, Tanaka M, Iwanura Y (1996) Coding of modified body schema during tool use by macaque postcentral neurones. NeuroReport 7:2325-2330. CrossRef Medline

Isa T, Ohki Y, Seki K, Alstermark B (2006) Properties of propriospinal neurons in the C3-C4 segments mediating disynaptic pyramidal excitation to forelimb motoneurons in the macaque monkey. J Neurophysiol 95:3674-3685. CrossRef Medline

Ishibashi H, Hihara S, Iriki A (2000) Acquisition and development of monkey tool-use: behavioral and kinematic analyses. Can J Physiol Pharmacol 78:958-966. CrossRef Medline

Jackson A, Mavoori J, Fetz EE (2007) Correlations between the same motor cortex cells and arm muscles during a trained task, free behavior, and natural sleep in the macaque monkey. J Neurophysiol 97:360-374. CrossRef Medline

Jacobs S, Danielmeier C, Frey SH (2010) Human anterior intraparietal and ventral premotor cortices support representations of grasping with the hand or a novel tool. J Cogn Neurosci 22:2594-2608. CrossRef Medline

Johnson-Frey SH (2004) The neural bases of complex tool use in humans. Trends Cogn Sci 8:71-78. CrossRef Medline

Kinoshita M, Matsui R, Kato S, Hasegawa T, Kasahara H, Isa K, Watakabe A, Yamamori T, Nishimura Y, Alstermark B, Watanabe D, Kobayashi K, Isa $\mathrm{T}$ (2012) Genetic dissection of the circuit for hand dexterity in primates. Nature 487:235-238. CrossRef Medline

Kraskov A, Dancause N, Quallo MM, Shepherd S, Lemon RN (2009) Corticospinal neurons in macaque ventral premotor cortex with mirror properties: a potential mechanism for action suppression? Neuron 64:922-930. CrossRef Medline

Kraskov A, Prabhu G, Quallo MM, Lemon RN, Brochier T (2011) Ventral premotor-motor cortex interactions in the macaque monkey during grasp: response of single neurons to intracortical microstimulation. J Neurosci 31:8812-8821. CrossRef Medline

Kuypers HG (1981) Anatomy of the descending pathways. In: Handbook of physiology: the nervous system II (Brookhart JM, Mountcastle VB, eds), pp 597-666. Bethesda, MD: American Physiological Society.

Lawrence DG, Kuypers HG (1968) The functional organization of the motor system in the monkey. I. The effects of bilateral pyramidal lesions. Brain 91:1-14. CrossRef Medline

Lemon RN (1993) Cortical control of the primate hand. Exp Physiol 78: 263-301.

Lemon RN (2008) Descending pathways in motor control. Annu Rev Neurosci 31:195-218. CrossRef Medline

Lemon RN, Griffiths J (2005) Comparing the function of the corticospinal system in different species: organizational differences for motor specialization? Muscle Nerve 32:261-279. Medline

Lemon RN, Mantel GW, Muir RB (1986) Corticospinal facilitation of hand muscles during voluntary movement in the conscious monkey. J Physiol 381:497-527. Medline

Leyton SS, Sherrington CS (1917) Observations on the excitable cortex of the chimpanzee, orangutan and gorilla. Q J Exp Physiol 11:135-222.

Maier M, Bennett KM, Hepp-Reymond MC, Lemon RN (1993) Contribution of the monkey cortico-motoneuronal system to the control of force in precision grip. J Neurophysiol 69:772-785.

Maier MA, Kirkwood PA, Nakajima K, Lemon RN (2005) The importance of direct vs. indirect corticospinal connections for dexterity and their evolution. In: Knapping stone: a uniquely hominid behavior? McDonald Institute Monograph (Roux V, Bril B, eds), Cambridge, UK: Cambridge UP.

McKiernan BJ, Marcario K, Karrer JH, Cheney PD (1998) Corticomotoneuronal postspike effects in shoulder, elbow, wrist, digit, and intrinsic hand muscles during a reach and prehension task. J Neurophysiol 80:1961-1980. Medline

McKiernan BJ, Marcario JK, Karrer JH, Cheney PD (2000) Correlations between corticomotoneuronal (CM) cell postspike effects and cell-target muscle covariation. J Neurophysiol 83:99-115. Medline

Muir RB, Lemon RN (1983) Corticospinal neurons with a special role in precision grip. Brain Res 261:312-316. CrossRef Medline

Nakajima K, Maier MA, Kirkwood PA, Lemon RN (2000) Striking differences in the transmission of corticospinal excitation to upper limb motoneurons in two primate species. J Neurophysiol 84:698-709. Medline

Obayashi S, Suhara T, Nagai Y, Maeda J, Hihara S, Iriki A (2002) Macaque prefrontal activity associated with extensive tool use. NeuroReport 13: 2349-2354. CrossRef Medline

Okanoya K, Tokimoto N, Kumazawa N, Hihara S, Iriki A (2008) Tool-use training in a species of rodent: the emergence of an optimal motor strategy and functional understanding. PLoS One 3:e1860. CrossRef Medline

Peeters R, Simone L, Nelissen K, Fabbri-Destro M, Vanduffel W, Rizzolatti G, Orban GA (2009) The representation of tool use in humans and monkeys: common and uniquely human features. J Neurosci 29:11523-11539. CrossRef Medline

Phillips CG (1971) Evolution of the corticospinal tract in primates with special reference to the hand. In: Proceedings of the Third International Congress of Primatology, pp 2-23. Zurich: Karger.

Porter R, Lemon RN (1993) Corticospinal function and voluntary movement. In: Physiological society monograph. Oxford, UK: Oxford UP.

Quallo MM, Price CJ, Ueno K, Asamizuya T, Cheng K, Lemon RN, Iriki A (2009) Gray and white matter changes associated with tool-use learning in macaque monkeys. Proc Natl Acad Sci U S A 106:18379-18384. CrossRef Medline

Quian Quiroga R, Nadasdy Z, Ben-Shaul Y (2004) Unsupervised spike detection and sorting with wavelets and superparamagnetic clustering. Neural Comput 16:1661-1687. CrossRef Medline

Rathelot JA, Strick PL (2006) Muscle representation in the macaque motor cortex: an anatomical perspective. Proc Natl Acad Sci U S A 103:8257-8262. CrossRef Medline

Rathelot JA, Strick PL (2009) Subdivisions of primary motor cortex based on cortico-motoneuronal cells. Proc Natl Acad Sci U S A 106:918-923. CrossRef Medline

Ro JR, Debowy D, Ghosh S, Gardner EP (2000) Depression of neuronal firing rates in somatosensory and posterior parietal cortex during object acquisition in a prehension task. Exp Brain Res 135:1-11. CrossRef Medline

Santello M, Flanders M, Soechting JF (1998) Postural hand synergies for tool use. J Neurosci 18:10105-10115. Medline

Schieber MH, Rivlis G (2005) A spectrum from pure post-spike effects to synchrony effects in spike-triggered averages of electromyographic activity during skilled finger movements. J Neurophysiol 94:3325-3341. CrossRef Medline

Schieber MH, Santello M (2004) Hand function: peripheral and central constraints on performance. J Appl Physiol 96:2293-2300. CrossRef Medline

Shimazu H, Maier MA, Cerri G, Kirkwood PA, Lemon RN (2004) Macaque ventral premotor cortex exerts powerful facilitation of motor cortex outputs to upper limb motoneurones. J Neurosci 24:1200-1211. CrossRef Medline

Shurcliff A, Brown D, Stollnitz F (1971) Specificity of training required for solution of a stick problem by rhesus monkeys (Macaca mulatta). Learn Motiv 2:255-270. CrossRef

Smith AM, Hepp-Reymond MC, Wyss UR (1975) Relation of activity in precentral cortical neurons to force and rate of force change during isometric contractions of finger muscles. Exp Brain Res 23:315-332. Medline

Spinks RL, Baker SN, Jackson A, Khaw PT, Lemon RN (2003) The problem of dural scarring in recording from awake behaving monkeys: a solution using 5-flurouracil. J Neurophysiol 90:1324-1332. CrossRef Medline

Takei T, Seki K (2010) Spinal interneurons facilitate coactivation of hand muscles during a precision grip task in monkeys. J Neurosci 30:17041-17050. CrossRef Medline

Umilta MA, Brochier TG, Spinks RL, Lemon RN (2007) Simultaneous recording of macaque premotor and primary motor cortex neuronal populations reveals different functional contributions to visuomotor grasp. J Neurophysiol 98:488-501. CrossRef Medline

Umilta MA, Escola L, Intskirveli I, Grammont F, Rochat M, Caruana F, Jezzini A, 
Gallese V, Rizzolatti G (2008) When pliers become fingers in the monkey motor system. Proc Natl Acad Sci U S A 105:2209-2213. CrossRef Medline

van Schaik CP, Deaner RO, Merrill MY (1999) The conditions for tool use in primates: implications for the evolution of material culture. J Hum Evol 36:719-741. CrossRef Medline

Visalberghi E, Fragaszy DM, Savage-Rumbaugh S (1995) Performance in a tool-using task by common chimpanzees (Pan troglodytes), bonobos (Pan paniscus), an orangutan (Pongo pygmaeus), and capuchin monkeys (Cebus apella). J Comp Psychol 109:52-60. CrossRef Medline

Warden CJ, Koch AM, Fjeld HA (1940) Instrumentation in Cebus and Rhesus monkeys. J Gen Psychol 56:297-310.

Yamazaki Y, Echigo C, Saiki M, Inada M, Watanabe S, Iriki A (2011) Tooluse learning by common marmosets (Callithrix jacchus). Exp Brain Res 213:63-71. CrossRef Medline 